\title{
Highlights of the 25th Conference of the European Society for Microcirculation
}

\author{
Integrating Vascular Biology \& Medicine: Basic and Clinical Science \\ August 26-29, 2008, Budapest, Hungary
}

\author{
Akos Koller ${ }^{\mathrm{a}, \mathrm{b}, \mathrm{c}}$ Zsolt Bagic \\ a Department of Pathophysiology and Gerontology, University of Pécs, Pécs, \\ ${ }^{b}$ Department of Pathophysiology, Semmelweis University, Budapest, Hungary; \\ 'Department of Physiology, New York Medical College, Valhalla, N.Y., USA
}

The 25th Conference of the European Society for Microcirculation (ESM) was held in Budapest in Hungary, in August 26-29, 2008. The meeting was a celebration of the 50th anniversary of ESM, since the meeting is biannual. Three comprised excellent summative review lectures by plenary speakers, series of symposia, oral and posters presentations of broad spectrum of current microvascular and vascular biology research took place. The meeting was attended about 420 scientists from all over the world. Importantly, a significant number of investigators came from Eastern Europe, according to the plan of the organizers, whose aim was to extend the 'border' of ESM. Several on-site exhibitors of state-of-the-art tools and equipments used in microvascular research and molecular biology facilitated the development of techniques and methods of investigations. In this summary key topics are selected from the Conference, representing the current and future directions of the microvascular and lymphatic research and vascular biology investigations.

A full listing of abstracts are available through the Journal of Vascular Research (www.karger.com/doi/10.1159/000144991). The complete meeting report is available at www.karger.com/doi/10.1159/000243977.

(C) 2009 S. Karger AG, Basel 


\section{NOVEL MECHANISMS OF CARDIOVASCULAR REGULATION IN HEART FAILURE AND SHOCK.}

\section{a) Renin-angiotensin system and vascular effects in heart failure"}

The substantial changes in peripheral circulation is chronic heart failure CHF) that are connected to the activity of central nervous system were summarized by $\mathrm{IH}$ Zucker [1]. Their studies have shown that $\mathrm{CHF}$ is characterized by activation of the sympathetic nervous system and the renin angiotensin II (Ang II) system. These compensatory mechanisms are beneficial in the early stages of CHF. However, prolonged activation exacerbates the CHF state causing further deterioration in cardiac and peripheral organ function. The mechanism by which central regulation of sympathetic outflow is controlled in the CHF state is not completely understood. Thus the role of Ang II and reactive oxidant stress (ROS) in the regulation of sympathetic tone in CHF have been extensively investigated. It was found that in most areas of the mid and hind brain that regulate sympathetic tone, both angiotensin type 1 (AT1) and type 2 receptors (AT2) are up regulated. For AT1 receptors this up regulation is totally dependent on Ang II binding. Chronic administration of the AT1 receptor antagonist losartan completely prevents AT1 receptor up regulation in the rostral ventrolateral medulla (RVLM) and paraventricular nucleus (PVN) of rabbits with pacing-induced CHF [2].

The molecular mechanism by which AT1 receptors are up regulated in heart failure or following increases in plasma Ang II involves the stimulation of the transcription factor Activator Protein 1 (AP1). AP1 is formed by the dimerization of two c-Jun or a c-Jun and a c-Fos molecule. In rabbits with $\mathrm{CHF}$, enhanced AP1 binding to the promoter region of the AT1 receptor gene was observed along with an increase in c-Jun and Jun Kinase (JNK). The upregulation in AT1 receptor protein could be inhibited by JNK inhibitors or losartan, but not by inhibitors of ERK or p38 MAPK. Ang II signaling involves an $\mathrm{NAD}(\mathrm{P}) \mathrm{H}$ Oxidase mediated superoxide production in the RVLM, nucleus of the tractus solitarius (NTS) and PVN. CHF rabbits exhibit an increase in several of the protein subunits of the NAD(P)H oxidase enzyme. The sympatho-excitation in the CHF state can be reduced following central treatment with free radical scavengers or $\mathrm{NAD}(\mathrm{P}) \mathrm{H}$ oxidase inhibitors [3].

Ang II may also mediate an increase in sympathetic neuronal excitability by causing a chronic down regulation of potassium channel proteins. In the CHF state or in neuronal cell cultures incubated with Ang II, the Kv4.3 channel protein was observed to be downregulated along with a decrease in potassium channel current. Nitric Oxide (NO) may play an important role in the sympatho-excitation in CHF. Nitric Oxide Synthase (NOS) is downregulated in the PVN and RVLM in the CHF state. NO, being a 
sympatho-inhibitory substance may contribute to sympatho-excitation when its synthesis is decreased. Interventions that increase NO biosynthesis, such as adenoviral gene transfer, exercise training and statin treatment all reduce the sympatho-excitation in CHF [4].

\section{b) Angiotensin II Type 2 Receptor in the Control of Vascular Resistance}

In the vascular wall two major types of angiotensin II receptors are known: the Ang II type 1 receptor (AT1R) and type 2 receptor (AT2R) [5]. Angiotensin II, through activation of the ubiquitously expressed $\mathrm{AT}_{1} \mathrm{R}$, induces vasoconstriction, fluid and electrolyte homeostasis as well as trophic effects involved in vascular and cardiac remodeling. On the other hand, AT2R is highly expressed in fetal tissue, whereas in adults it is expressed in heart, kidney, adrenal gland, brain, uterus, and both endothelial and vascular smooth muscle cells. Widdop et al, using in vivo models [6], has consistently shown that AT2R opposes the pressor action of angiotensin II and his group has recently shown that this effect is higher in female rats chronically infused with angiotensin II [7].

Marc de Gasparo finding suggest a functional cross-talk between AT1R and AT2R in post-ischemic revascularization, whereas AT1R stimulation promotes angiogenesis and that AT2R counteracts this effect through activation of apoptosis [8]. Hind limb revascularization after femoral ligature is reduced in AT2R knockout mice [9]. Indeed, in "critical" situations such as ischemia, and most probably in relation to inflammation, the AT2R is overexpressed in vascular cells and especially in smooth muscle cells [9]. Studies of Gervaise and Loirand identified a new pathway linking AT2R to RhoA inhibition and consequently vasodilation in smooth muscle cells. Indeed, AT2R stimulation activates the Ser/Thr kinase Ste20 related kinase (SLK) which then induces Ser188 phosphorylation of RhoA, thus counteracting AT1R-induced activation of RhoA and contraction [10]. This interaction between AT1R and AT2R might be critical in pathological situations. In hypertensive rats or in normotensive old rats
AT2R stimulation induces a contraction, which is reversed, at least in hypertensive animals into dilation when blood pressure is efficiently reduced [6]. In old rats AT2Rmediated contraction relies mainly on superoxide production [11]. Similarly, in diabetic rats superoxide production is involved in the reduction in AT2R-mediated dilation of resistance arteries [12]. Thus, although the importance of the balance between AT1R and AT2R stimulation in vascular homeostasis is now clearly established it remains to uncover the mechanisms involved in the dramatic changes in the type of response induced by AT2R stimulation in pathological situations.

\section{c) Endocannabinoids and Cardiovascular Regulation}

The exploding research on cannabinoid, which used to be an esoteric field of interest to a handful of scientists only, was summarized by G. Kunos. This has changed dramatically as a result of a number of landmark discoveries in the past 20 years as summarized by Kunos`s group recently [13]. The identification of specific cannabinoid receptor binding sites in the brain was followed by the cloning of two, G protein-coupled cannabinoid receptors in the early 1990s. CB1 receptors are expressed at very high levels in the brain, but are also expressed at much lower, yet functional, levels in most peripheral tissues, whereas CB2 expression is largely limited to cells of the immune and hematopoietic systems [13].

The existence of mammalian receptors for a plant-derived substance led to the search for and discovery in the mid 1990s of endogenous ligands, which turned out to be arachidonic acid metabolites, generated on demand from membrane phospholipids precursors. The two most widely studied endocannabinoids are arachidonoyl ethanolamide named anandamide and 2arachidonoylglycerol or 2-AG [13]. Research into the possible physiological functions of these ligands was greatly facilitated by the introduction of selective $\mathrm{CB} 1$ and $\mathrm{CB} 2$ receptor antagonists and also by the generation of mouse strain deficient in these 
receptors. These tools allowed the uncovering of the regulatory or modulatory role of endocannabinoids in a growing number of physiological processes, both in the brain and in peripheral tissues, many of which had been suspected based on age-old knowledge about the effects of plant-derived cannabinoids. For example, the psychoactive ingredient of marihuana, delta-9-THC, has long been known to also have cardiovascular effects: in experimental animals it causes long lasting hypotension and also antagonizes various forms of hypertension, whereas in humans it usually causes isolated tachycardia on acute administration, but can also cause hypotension when taken chronically.

The discovery of the first endocannabinoid, anandamide was done by Raphael Mechoulam in 1992, followed by the investigation of the effect and role of anandamide in the cardiovascular system. In anesthetized mice anandamide caused changes in blood pressure and heart rate similar to those caused by THC: an initial pressor response followed by longer lasting hypotension and bradycardia [14]. The hypotension and bradycardia are mediated by CB1 receptors, as indicated by the complete absence of a hypotensive/bradycardic response to anandamide, THC as well as two synthetic analogs in CB1 receptor knockout mice [14]. The profound and long lasting hypotension caused by some potent synthetic cannabinoid analogs suggested that endocannabinoids may be involved in pathological states associated with hypotension, such as various forms of shock. In a hemorrhagic shock model it was found that the selective CB1 antagonist rimonabant was able to partially reverse the hypotension and, more interestingly, infusing whole blood or its monocyte fraction from animals in shock into normal recipient rats caused hypotension reversible by rimonabant. Then it could be demonstrated that monocytes from 'shocked' but not control animals contained measurable levels of anandamide, as detected by gas chromatography/mass spectrometry [15].

In a rat model of endotoxin shock, rimonabant similarly prevented the acutephase hypotension, but not the tachycardia, caused by treatment of rats with bacterial endotoxin (LPS). Macrophages are the primary cellular targets of LPS due their expression of the CD14 protein, and macrophages isolated from LPS-treated rats caused similar, rimonabant-sensitive hypotension. Again, LPS-treated, but not control macrophages contained measurable levels of anandamide. Since activated macrophages express cell adhesion molecules that cause them to temporarily adhere to the vascular endothelium, we proposed a paracrine mechanism whereby activated macrophages not only produce a vasodilator mediator but also deliver it to the site of action [16].

These results implicated that endocannabinoids as major hypotensive mediators in various forms of shock and related conditions, targeting both the vasculature and cardiac contractility. Endocannabinoids may function as a compensatory mechanism in hypertension. Indeed, they recently reported [17] that rimonabant, which does not influence blood pressure in normotensive rats, causes a marked pressor response in 3 different models of hypertension, including the spontaneously hypertensive rat, whereas both anandamide and an inhibitor of fatty acid amidohydrolase, the enzyme responsible for the degradation of anandamide in vivo, normalize blood pressure in hypertension with little or no effect in normotensive controls. In conclusion, endocannabinoids do not participate in cardiovascular regulation under normotensive conditions, but become tonically active in pathological states: they contribute to the hypotension in various forms of shock, and act as a compensatory mechanism in hypertension.

\section{MICROCIRCULATION IN OBESITY AND METABOLIC DISEASE}

\section{a) Microvascular Actions of Insulin in Muscle and Underlying Mechanisms}

There is growing evidence that insulin-mediated glucose uptake by muscle is dependent on microvascular perfusion and that a possible cause of insulin resistance is an 
impairment of insulin-mediated capillary recruitment in this tissue. Rattigan et al found that a number of methodologies such as biochemical reporter of capillary blood flow, microdialysis of tracers, Laser Doppler implantable probes, and contrast enhanced ultrasound that have each shown microvascular perfusion to be stimulated by insulin and that this process to be impaired in insulin resistant states [18]. It has been also [19] reported by using Laser Doppler implantable probes that insulin-mediated capillary recruitment in muscle was specifically associated with an increase in myogenic vasomotion $(0.06-0.3 \mathrm{~Hz})$, and that this was completely blocked in insulin resistance. Studies of Ellmerer et al highlighted the situation where insulin action on the muscle microvasculature may be controlled by "cross-talk" from subcutaneous adipocytes [19]. Using interstitial fluid sampling by lymph drainage as a technique for assessing insulin action on muscle perfusion, data were shown for dogs that clearly supported a role of insulin in the regulation of muscle perfusion and that this was impaired in insulin resistance that had been induced by fat feeding [19]. In humans the findings were less clear, but this was largely due to technical difficulties. Bakker et al examined insulin signaling mechanisms in the endothelium with focus on the effects of fat cell derived palmitic acid, $\mathrm{TNF} \alpha$ and adiponectin using isolated rat cremaster resistance arteries in a pressure myograph. In this system insulin increased both $\mathrm{NO}$ and endothelin-1 actions [20]. Palmitic acid and TNF $\alpha$ each blocked NO production by selective inhibition of Akt signaling. This inhibition was shown to be due to the activation of two kinases, c-jun $\mathrm{N}$-terminal kinase (JNK) and protein kinase $\mathrm{C}$ theta $(\mathrm{PKC} \theta)$ in the vascular endothelium [20]. In contrast, new data revealed that adiponectin potentiated the insulin-mediated vasodilator action by inhibiting endothelin-1 production by an AMPK-dependent inhibition of insulinmediated activation of extracellular-regulated kinase 1/2 (ERK1/2).

The vascular smooth muscle signaling mechanisms under-pinning insulin action on the vasculature is also of interest as demonstrated by Doronzo et al [21]. The main pathways identified were the phosphatidylinositol-3-kinase (PI3-K) and mitogen activated protein kinase (MAPK), where these are thought to be responsible for the anti- and pro-atherogenic actions of insulin, respectively. The two pathways cooperate for the synthesis and secretion of hypoxia-inducible factor (HIF) and vascular endothelial growth factor (VEGF) [21]. New findings revealed that in two models of insulin resistance, the obese Zucker rat and in a fat fed rat there is a similar resistance in both pathways, even though fatty acids induce a specific resistance in the PI3-K pathway.

\section{b) New Insights into the Regulation of Functional Blood Flow in Obesity}

Obesity has been shown to impair functional vasodilatation and thus blood flow in response to exercise. In obesity there is an impaired endothelium-dependent function due to alterations in nitric oxide, prostacyclin and thromboxane, leading to alterations in blood flow. Prostacyclin has been shown to be important in functional vasodilation during exercise. Hester at al [22] proposed that the impaired functional vasodilation in obesity is due to an imbalance between the vasodilator prostacyclin (PGI2) and the vasoconstrictors thromboxane and its precursor, prostaglandin H2. In vitro experiments demonstrate that PGI2 release is impaired from isolated arteries, which may be due to the observed nitration of PGI2 synthase. PGI2 causes dilation though activation of KATP channels which are also inhibited in obesity [23]. Rosiglitazone (PPAR $\gamma$ activator) treatment, which improves insulin resistance and oxidative stress, increases functional vasodilation via diminished thromboxane receptor (TP) activation and increased KATP channel function in OZR [24]. Together these results suggest that insulin resistance and the resultant increase in ROS in obesity can have inhibitory effects on vascular responses to exercise.

In animal models of obesity, a number of cardiovascular dysfunctions, including impaired endothelium-dependent vasodilation, increased sympathetic activation 
of blood pressure and inward microvascular remodeling have been described $[25,26]$. A genetically modified mouse model on the $\mathrm{db} / \mathrm{db}$ (leptin receptor deficient mouse) background was generated to produce obese mice deficient protein tyrosine phosphatase 1B (PTP1B), a termination pathway for insulin signaling by Stepp and coworkers (meeting abstract). These dual knockout $\mathrm{db} / \mathrm{db}$ PTP1B null mice remained morbidly obese, but had corrected markers of peripheral insulin resistance: improved glucose tolerance, reduced $\mathrm{HbA} 1 \mathrm{C}$ and normalization of dyslipidemia. Surprisingly, markers of hepatic insulin resistance, such as fasting glucose or hyperinsulinemia persisted, suggesting that deletion of PTP1B in $d b / d b$ mice specifically corrects peripheral insulin resistance. Compared to normal $\mathrm{db} / \mathrm{db}$ mice, PTP1B-null $\mathrm{db} / \mathrm{db}$ mice showed normalization of endothelial function and improved microvascular remodeling. Sympatho-activation of arterial pressure persisted despite deletion of PTP1B, indicating that other aspects of obesity account for this deficit. Taken together, these data indicate that specific relationships exist in obese individuals between risk factors and vascular dysfunctions and understanding these relationships will further our understand of cardiovascular disease in obesity.

Obesity also affects the role of endothelial glycocalyx properties as studied by VanTeeffelen et al [27]. Recently, by using tracer dilution of glycocalyx-selective tracers, glycocalyx properties in the systemic circulation in obese (and hyperglycemic, $\mathrm{db} / \mathrm{db}$ ) mice were assessed. It was found that exclusion of circulating blood was not affected compared to control $\mathrm{C} 57 \mathrm{Bl} / 6$ mice, yet exclusion of FITC-labeled $70 \mathrm{kDa}$ dextrans, having limited access to the glycocalyx in control mice, was impaired in the $\mathrm{db} / \mathrm{db}$ mice. Further, robust systemic leakage of the dextrans was observed in the $\mathrm{db} / \mathrm{db}$ mice. Treatment of the $\mathrm{db} / \mathrm{db}$ mice with metformin for 2 weeks resulted in an improvement of glycocalyx exclusion and barrier properties, without an effect on fasting blood glucose levels (meeting abstract). It was concluded that conditions of obesity and hyperglycemia are associated with compromised glycocalyx properties, but these can be partly reversed by metformin treatment.

Morawietz's group aimed to circumvent the limitations of standard organ chamber experiments using in vivo optical coherence tomography (OCT) to analyze the vascular function of small arteries of different mouse strains [28]. Vascular function of murine saphenous artery and vein of male C57BL/6 (WT) and LDLR knockout (LDLR k.o.) mice after a 14 week feeding period of control or high-fat diet. By using OCT technique they were able to image the impaired vascular function of small arteries of different mouse strains in response to high-fat diet in vivo [29]. This imaging procedure offers the ability to display differences in early stages of atherosclerotic pathogenesis.

The study be Clough et al [30] assessed muscle microvascular function in 38 consented volunteers with two or more features of metabolic syndrome (central obesity, dyslipidaemia, high blood pressure and dysglycaemia), before and after 6 months lipid lowering therapy (Atorvastatin 40mg o.d.) or placebo control. Filtration capacity (Kf), isovolumetric pressure (Pvi) and resting limb blood flow (Qa) were measured using strain gauge plethysmography. At baseline, Kf was negatively correlated with overall CVD risk, visceral fat, insulin resistance, LDL Cholesterol, HbA1c, markers of inflammation and age $(r>0.4, p<0.05)$, and positively correlated with HDL cholesterol. Qa was related to activity $(\mathrm{r}=0.42, \mathrm{p}=0.03)$. These individuals also showed a marked decrease in dilator capacity. While statins lowered LDL cholesterol, they had little effect on any of our microvascular measures. These data suggested attenuation in capacity for blood/tissue exchange in people with features of metabolic syndrome. Although statins are known to decrease risk of CVD, Clough et al were unable to show any improvements in microvascular function over the 6 months study [30].

Finally, Bagi et al proposed the existence of several adaptive mechanisms that may maintain the dilatory function of coronary microvessels in obesity. Among others, increased production of hydrogen 
peroxide [31], cyclooxygenase-2-derived dilator prostaglandins $[32,33]$ as well as activation of soluble guanylate cyclase in vascular smooth muscle cells have been suggested to maintain or enhance the dilatory function of coronary microvessels [34, 35]. These adaptive mechanisms the coronary microcirculation seems to be important, since clinical studies have demonstrated that a potential interference with these adaptive signaling mechanisms, such as by the use prostaglandin synthesis inhibitors and antioxidants would paradoxically temper the dilator function of coronary microvessels, predisposing these patients to tissue ischemia.

\section{WALL SHEAR STRESS AND RHEOLOGY IN MICROVASCULAR FLOW REGULATION}

\section{a) Role of the Arterioles in Regulating the Circulation}

The purpose of the studies of Johnson and Intaglietta was to re-examine the overall regulation of the circulation by introducing intrinsic regulatory mechanisms of the arterioles; specifically, autoregulation of blood flow, i.e. the tendency of blood flow to be independent of arterial pressure. They proposed that at a very fundamental level, the interaction between intrinsic regulatory mechanisms of the heart (Starling's Law) and the autoregulatory mechanisms of the microcirculation determine arterial pressure and cardiac output. In the past, much emphasis has been placed on the role of the central nervous system and neural reflexes in regulation of the circulation via a "set point" for arterial pressure. We propose that neural control mechanisms modify, rather than set overall regulation, by altering factors, such as heart rate and contractility, vascular resistance and venous compliance. A conceptual model based on this principle predicts the observed effects of decreasing vascular resistance, static exercise and dynamic exercise on cardiac output and arterial pressure. Thus adjusting supply to match demand by coupling intrinsic regulatory mechanisms of the heart to those of the arterioles would in principle more effectively maintain homeostasis of the tissues than if the central nervous system sets arterial pressure by adjusting supply and demand.

\section{b) Microvascular Benefits of Increasing Plasma Viscosity and Maintaining Blood Viscosity: Experimental and Clinical Findings}

Effects of changes in blood viscosity were always an exiting field of basic and clinical investigations. Intaglietta pointed out that intentionally or accidentally decreasing blood viscosity is supposed to be beneficial while the perception that increased blood viscosity promotes or is a consequence of diseases is embodied in the literature [36]. However, increasing blood viscosity in the healthy organism increases shears stress and NO production, causing vasodilatation [36]. Changing blood viscosity linearly affects peripheral resistance, having a highly nonlinear opposite effect on the corresponding anatomical component. A microvascular consequence is that blood oxygen carrying capacity can be lowered beyond established transfusion triggers if plasma viscosity is increased, since vasodilatation maintains functional capillary density and increases microvascular flow due to the lowered blood viscosity as shown by Intaglietta et al [36].

Hemorrhagic shock resuscitation improves using high viscosity plasma expanders, and hypertonic-hyperviscosus resuscitation is more effective than hypertonic-hyperoncotic resuscitation. Moderate (isovolemic) increases of hematocrit cause hypotension. In the normal population elevated hematocrit causes a nonstatistical elevation of blood pressure (MAP). The MAP vs. hematocrit distribution in diabetic type 2 patients is "U" shaped and treatment of these patients increases hematocrit and lowers glucose and blood pressure [37]. Treatment of hypertension with diuretics increases hematocrit and lowers blood viscosity. Thus increased or maintained blood/plasma viscosity has a counter intuitive, potentially beneficial microvascular effect that translates into a health benefit. Understanding the complexity of the 
microcirculation is necessary for development of effective blood substitutes that can be used to transfusion and emergency medicine, cancer, ischemia, and the heart-lung machine [38].

\section{c) Wall Shear Stress Regulation in Various Segments of Microcirculation}

During changes in blood flow velocity and/or viscosity wall shear stress (WSS) can change substantially. However estimation of WSS and characterization of its effects on microvascular resistance in various segment of circulation are still not clearly elucidated. For example, in vivo studies of Reneman's group have shown that mean wall shear stress (WSS) is far from constant along the arterial tree, as predicted by the law of minimal energy discharge, and may substantially deviate from the theoretically predicted value of $1.5 \mathrm{~Pa}$ [39]. In man only in the common carotid artery mean WSS, being on the average $1.2 \mathrm{~Pa}$, approximates this theoretical value as described by Reneman [39]. In the brachial (0.4-0.5 $\mathrm{Pa})$ and femoral arteries (0.3-0.5 Pa) mean WSS is on the average substantially lower. Also in arterial bifurcations differences in mean WSS have to be appreciated. Mean WSS is higher in arterioles than in arteries. Across species mean WSS in a particular artery decreases linearly with body mass, e.g., in the descending aorta from $8.8 \mathrm{~Pa}$ in mice to 0.5 $\mathrm{Pa}$ in humans (flow velocities being similar). These observations imply that (1) Murray's cube law on flow-diameter relations cannot be applied to the whole arterial system; the exponent of the power law varies from 2 in large elastic arteries to 1.55 in coronary arteries and to 3 in the microcirculation and (2) in in vitro investigations no average calculated shear stress value can be taken to study shear stress effects on endothelial cells derived from different vascular areas or from the same artery in different species [40].

Also, recent studies of Koller's group have shows that there are significant differences in the regulation of WSS in arterioles and venules [41, 42]. Increases in WSS (either by increases in flow velocity or fluid viscosity) has been shown to induce substantial endothelial-dependent dilation at the arterial side [41]. The pronounced dilation in arterioles is mediated by the release of nitric oxide (NO), dilating prostaglandins (PGs) and reactive oxygen species [43, 44]. Interestingly, similar increases in WSS elicit far less pronounced dilation in venules, due to tempering effects of released constrictive prostaglandins, in addition to the release of NO and PGs [42]. These observations indicate that WSS is regulated by different mechanisms in arterioles and venules, either through wall shear rate or apparent viscosity. The few studies performed up to date interestingly show that the vascular response of cerebral arterial vessels to an increase of WSS is constriction [45]. Nor the exact mechanism of action nor the physiological role of this response has been elucidated. Nevertheless one can hypothesize that flowinduced constriction of cerebral vessels may aim to control intracerebral volume.

In addition to the previously described steps in the mechanotransduction of WSS recent studies of Vink et al suggests an important role of the glycocalyx in sensing and transducing shear forces to endothelial cells [45]. Upon removal of glycocalyx glycosaminoglycans endothelial cells loose their ability to adapt to changes in flow conditions, i.e., no effect of shear stress on cell alignment and migration behavior. On the other hand exposure of the glycocalyx to shear forces trigger glycocalyx synthesis and disease. In areas prone to atherogenesis where WSS is low the glycocalyx was found to be significantly thinner [46]. Thinner glycocalyx are associated with increased permeability for albumin and fatty acids and possibly with enhanced adhesion of leucocytes. A challenging question to be asked is whether thinning of glycocalyx is an early step in disease processes and, therefore, can be used to identify early vascular changes in such disorders as atherosclerosis and diabetes [47].

\section{ADAPTATION OF MICROCIRCULATION}

a) Angiogenesis and Microvascular Remodeling. Role of Mechanical Factors in 
Angiogenesis in Skeletal Muscle. - The Malpighi Award Lecture (Olga Hudlicka)

Exercise training results in capillary growth in muscles predominantly involved in the type of training: in those composed mainly of oxidative fibers with endurance training, in those composed of glycolytic fibers in sprint or exhaustive exercise. Using chronic electrical stimulation of one muscle group as a model of exhaustive exercise and comparing its effect with long term vasodilator (prazosin) induced increases in blood flow; the importance of blood flow and increases capillary shear stress in the initiation of capillary growth have been demonstrated [48]. High blood flow in muscles of stimulated and prazosin-treated animals results in increased capillary proliferation and raised expression of VEGF in capillaries. Increased shear stress found in 2 days stimulated muscles even at rest was linked with raised expression of VEGF and VEGFR2 protein [48]. Inhibition of eNOS by long-term administration of L-NNA suppressed stimulation-induced increases in capillary shear stress and VEGF and VEGFR2 expression and eliminated capillary proliferation and increase in capillary/fiber ratio. It also suppressed capillary growth in muscles of prazosin-treated mice [49]. Thus nitric oxide plays an important role in increased blood flow/shear stress induced angiogenesis.

\section{b) Angiogenesis and Molecular Diversity of VEGF-A}

The latest investigation on novel aspects of $\mathrm{VEGFb}$ activity, its role in development and its mechanism of action reveal novel mechanisms. The VEGFb activity, its role in development and its mechanism of action were studied by Bates et al [50]. Their recent data show that VEGFb inhibits choroidal neovascularisation (the cause of wet age related macular degeneration) and metastatic melanoma spread in mice, and that the VEGFb isoforms formed half or more of the total VEGF in normal-non angiogenic tissues [51]. Work from Bates's laboratory, investigate the recent advances in understanding how VEGFb expression is regulated by growth factors and splice factors, and the role of ASF/SF2 and SRp55 phosphorylation by SRPK and Clk family kinases respectively regulate splice site choice, and hence the balance of anti- to pro angiogenic isoforms [52]. In addition the group of Cupp [53] showed that VEGFb was involved in mouse development of reproductive organs, - inhibiting endogenous $\mathrm{VEGFb}$ resulted in increased angiogenesis in the testis, and increased maturity of antral follicles in the developing ovary. Another aspect of this issue is address in studies of Hofer et al, showing that VEGFb acts by partially activating the VEGFR2 to result in signaling that prevents angiogenesis, and provided evidence that this was due to its inability to bind neuropilin [54] (meeting abstract). The mechanisms of VEGF receptor binding was elucidated, and explained the mechanism of the anti angiogenic effect of $\mathrm{VEGFb}$. Interestingly, studies of Leach et al showed that VEGFb was downregulated in diabetic placenta, and could be switched off by excess insulin perfusion (meeting abstract).

\section{c) Exercise-Induced Vascular Adaptations}

During exercise there is a powerful stimulus for local dilatation within the active muscle that can increase blood flow as much as 20 -fold. While there has been much research activity attempting to elucidate the mechanistic basis for this local dilatation, there has been no comprehensive study that establishes the factors involved and their coordination [55]. Studies employing inhibition have show interactions between the nitric oxide system and the cyclooxygenase and cytochrome P450 systems. More recently, plasma ATP and adenosine infusion have been implicated, as more recent work has demonstrated massive increases in blood flow of resting muscle similar to that observed during intense exercise [56]. Hellsten et al presented evidence that ATP and adenosine induces release of nitric oxide and prostaglandins [56]. Adenosine's role in exercise hyperemia appears to be primarily determined through the adenosine receptor 
leading to the release of these vasodilatations. In contrast, adenosine activation of its receptors on vascular smooth muscle appears to be less important. Thus, the interactions among a number of important dilators appear to be coordinated to affect the very high blood flows possible in very active muscle [56].

Earlier work showed that endothelialdependent vasoresponsiveness in rat aorta is enhanced by exercise training. Subsequent work of Chao and Yang provided evidence that the markedly reduced endothelialmediated dilatory response to insulin caused by estrogen deficiency can be reversed by exercise training. Chronic exercise was effective at improving vasoresponsiveness by increases via PI3K and nitric oxide synthase pathways [57]. In contrast, direct smooth muscle vasoresponsiveness of vessels from ovariectomized animals was unaltered by chronic exercise. This evidence implies that chronic exercise would be useful in reversing the reduced endothelial mediated responsiveness of vessels, apparent with the loss of normal estrogen influence [57].

Chronic physical activity is also known to be an effective means of improving the exercise tolerance, ability for daily activity, and overall outlook on life of patients with peripheral arterial insufficiency. Meaningful adaptations induced by chronic activity include microvascular (enhanced capillarity in active muscles) and conduit vessel enlargement (increased collateral blood flow) [58]. Increased flow through a vessel is a major stimulus for vascular remodeling via an increase in shear stress. Enlargement of preexisting vessels (arteriogenesis) that form the collateral circuit, have been routinely observed in preclinical animal models of peripheral arterial insufficiency [58]. This vessel enlargement requires effective $\mathrm{NO}$ signaling, as NOS inhibition eliminates the increase in collateral blood flow in preclinical animal models of peripheral arterial insufficiency. However, the increase in muscle capillarity, that is typical of endurance-type exercise training, is not eliminated [59]. Thus, there can be distinctions between the processes controlling arteriogenesis and angiogenesis. While virtually all studies have shown the benefits of enhanced physical activity in patients with intermittent claudication, there is only anecdotal evidence showing marked improvement in collateral blood flow [59]. It is presently unclear whether this is due to an inability to form significant collateral vessels (e.g., poor NO signaling), or an inadequate stimulus for their formation. Further, size and distance create distinct hemodynamic limitations in the development of a robust collateral circuit exist in humans, as compared to preclinical studies that employ small rodents. Additional work is needed to discern the conditions for meaningful vascular remodeling in patients with peripheral arterial insufficiency.

\section{d) Current ideas regarding the mechanisms contributing to the development of exercise hyperemia in the coronary circulation}

Contractile activity of skeletal and cardiac muscle during exercise produces large increases in oxygen consumption of these muscle tissues. For the high levels of oxygen consumption to be maintained during exercise, blood flow must be increased dramatically in both cardiac and skeletal muscle. Studies of Merkus and Dunker contributed significantly to our current understanding of the vascular adaptations involved in providing coronary blood flow during exercise [60]. Because the heart utilizes already $80 \%$ of the oxygen delivered by the coronary vasculature under basal resting conditions, any increase in myocardial oxygen consumption, such as occurs during exercise, and should be met by an increase in coronary blood flow. The coronary vasculature is compressed during each cardiac contraction and therefore perfusion of especially the subendocardium occurs mainly during diastole [61]. The driving force for myocardial perfusion can be calculated as the product of the duration of diastole and the effective perfusion pressure of the myocardium, i.e. the blood pressure- back pressure (assumed to be equal to the diastolic left ventricular pressure), and is called the diastolic pressure-time index (DPTI). An increase in heart rate during exercise results in a decrease in DPTI and therefore not only 
results in increased myocardial oxygen consumption, but also in an increase in extravascular compression [62]. Yet, despite the increase in extravascular compression, myocardial perfusion can increase up to fivefold during strenuous exercise [63, 64], which is accomplished by vasodilation of the coronary vasculature. Changes in control of vascular smooth muscle (relaxation of existing tone) produce decreased coronary vascular resistance and result in recruitment of coronary flow reserve to enable the increase in myocardial oxygen consumption.

Regulation of coronary vascular tone is a complex process that involves integration of signals from cardiomyocytes, the endothelium and neurohumoral influences to the vascular smooth muscle cells [63, 64]. These signals converge in signal transduction pathways that either alter opening of $\mathrm{K}$ channels $\left(\mathrm{K}^{+}{ }_{\mathrm{ATP}}, \mathrm{K}_{\mathrm{Ca},}^{+} \mathrm{K}_{\mathrm{v}}^{+}\right)$[65-69], thereby altering membrane potential and intracellular $\mathrm{Ca}$-concentration and/or affect Ca-sensitivity. Yet, despite intensive research by various groups, the individual contributions of these regulatory pathways, and their interactions, to exercise hyperemia in the coronary circulation are still incompletely understood. Studies in dogs, swine and humans have shown significant interspecies differences in control of coronary vasomotor tone [63].

The current knowledge about exercise hyperemia in swine is summarized by $\mathrm{D}$. Merkus. Signals from cardiac myocytes: Studies in which isolated cardiac myocytes were stimulated to contract at different rates, after which their bathing fluid was transferred to an isolated coronary arteriole suggest myocytes can communicate their metabolic needs to the coronary vasculature by altering production of adenosine [70], endothelin [70, 71] and $\mathrm{H}_{2} \mathrm{O}_{2}$ [72, 73]. Studies in vivo confirm a role for endothelin in exercise hyperemia (see also below), but do not show a change in the vasodilator influence of adenosine during exercise [74, 75], while the role of $\mathrm{H}_{2} \mathrm{O}_{2}$ still needs to be confirmed. Signals from the endothelium: The endothelium produces both vasodilators (NO and prostacyclin) and vasoconstrictors (endothelin). The vasodilator effect of NO and prostacyclin on the coronary vasculature is not altered during exercise [76]. Moreover, neither arterial, nor coronary venous plasma endothelin-levels are altered during exercise [75]. However, withdrawal of endothelininduced vasoconstriction contributes to recruitment of flow reserve in response to exercise $[70,75]$ and preliminary data suggest that the responsiveness of the coronary vasculature to endothelin is reduced. This reduction in coronary responsiveness to endothelin is mediated through $\mathrm{NO}$ and prostacyclin [77], which are known to be able to induce post-translational modification of the endothelin receptors [78] and may therefore result in altered signal transduction. Signals from neurohumoral systems: Exercise results in an increased activity of the autonomic nervous system as evidenced by an increase in circulating catecholamines [79]. Catecholamines can cause vasoconstriction through the alpha-adrenoceptors and vasodilation through the beta-adrenoceptors. Hence the net effect of an increase in catecholamines depends on the relative number of alpha- and beta-adrenoceptors. Because the coronary resistance vessels in swine lack alpha-adrenergic receptors, but do have beta-adrenergic receptors, betaadrenergic (feed-forward) vasodilatation contributes significantly to the recruitment of coronary flow reserve during exercise [80]. The renin-angiotensin system is also activated during exercise [79]. Yet, despite the increased plasma angiotensin-II levels during exercise, the contribution of the reninangiotensin system to regulation of coronary vasomotor tone is not altered [62, 81]. Integrated regulation of coronary vasomotor tone: The coronary vasculature receives signals from multiple vasoactive pathways. These signals are integrated to produce a response of vasodilatation or vasoconstriction. Most signal-transduction cascades eventually result in opening or closing of $\mathrm{K}^{+}$-channels in the vascular smooth muscle cells. In the coronary vasculature, $\mathrm{K}_{\text {ATP }}^{+}, \mathrm{K}^{+}{ }_{\mathrm{Ca}}$, and $\mathrm{K}_{\mathrm{V}}^{+}$ channels have been shown to be present and alterations in their opening-probability do contribute to exercise hyperemia in the coronary vasculature $[62,81]$.

The sensitivity to different vasoactive stimuli changes with vessel size [82]. The 
smallest coronary arterioles that are in closest proximity to the cardiac myocytes are most sensitive to stimuli from these myocytes. This enables the cardiac myocytes to fine-tune local blood flow to their needs. Changes in blood flow through these small arterioles then also change blood flow through the larger arterioles and smaller arteries upstream. These vessels are very sensitive to shear stress and an increase in blood flow will result in an increase in diameter, thereby recruiting these larger vessels to the process of exercise hyperemia [82]. The main advantage of having multiple vasodilator and vasoconstrictor pathways available to mediate the process of exercise hyperemia is that flow can be quickly and accurately matched to the needs of the myocardium. Moreover, when one system fails, other systems can take over to ensure adequate oxygenation of the myocardium, which is essential to maintain cardiac pump function.

\section{e) Control of Skeletal Muscle Vasculature by Physical Activity}

Studies of M.H. Laughlin at al focused on adaptations induced by chronic exercise training in skeletal muscle vascular beds. Accordingly, integration of current evidence indicates that training-induced vascular adaptation alters the determinants of skeletal muscle vascular resistance by at least two primary mechanisms [83]: 1) Altered vasomotor reactivity of arteries and arterioles and 2) Structural remodeling of the arterial tree. A number of studies demonstrate that exercise hyperemia in skeletal muscle is altered by exercise training, and that changes in control of vascular resistance play a limited role in increased blood flow capacity in skeletal muscle [83]. Evidence that physical activity induces both changes in vascular control and structure in skeletal muscle was summarized in this paper. Laughlin at al proposed that muscle fiber-type composition interacts with muscle fiber recruitment patterns during exercise so that the distribution of structural vascular adaptive changes induced by exercise training varies with the type of training preformed (ref). For example, high intensity exercise (high speed, uphill running) has been shown to produce the greatest relative increase in contractile activity in fast-twitch, white, skeletal muscle, like the white portion of the gastrocnemius muscle [84-88]. Following interval sprint training (IST), white gastrocnemius muscle exhibits the largest relative increase in oxidative capacity, capillary density, and blood flow capacity [85, 89]. In contrast, endurance exercise training (EX) has been shown to produce the greatest relative increase in contractile activity in the red portion of the gastrocnemius muscle (Gr) and the $\mathrm{Gr}$ muscle also exhibits the largest relative increase in oxidative capacity, capillary density, and blood flow capacity of the extensor muscles examined in rats following endurance exercise training [90-92]. Also, capillarity increases in the red portion of the gastrocnemius muscles in EX rats but is increased only in the white portion of the gastrocnemius muscle in IST rats, the limited magnitude of these changes indicates that increases in blood flow capacity of red and white gastrocnemius muscle following EX and IST training are not mediated solely by increased capillarization [89, 90]. More recent evidence indicates that changes in arteriolar density (number of arterioles $/ \mathrm{mm} 2$ ) contribute to regional increases in blood flow capacity within the gastrocnemius muscle and that exercise training induces increases in arteriolar density in muscle tissue with the greatest relative increase in fiber activity during training bouts [84]. Computational hemodynamic network model analysis of vascular casts indicate that the primary adaptation to IST is the formation of new arterioles which, in turn, creates an approximate doubling of flow capacity and a deeper penetration of high pressure into the arteriolar network [88].

\section{SIGNALING IN MICROCIRCUALTION}

\section{a) Estrogen Related Signaling and Regulation of Microvascular Resistance}

Studies of S. Duckles et al investigated the effects of estrogen on 
mitochondrial function in the cerebral circulation [93]. Their experiments on mitochondrial oxidative mechanisms in vascular tissues led to an interesting emergent concept: Mitochondrial production of reactive oxygen species (ROS) is an inevitable byproduct of energy production by oxidative phosphorylation. ROS activity is elevated by increased oxidative phosphorylation (following food intake, for example), or decreased ATP utilization (such as occurs with decreased exercise). Mitochondrial oxidative damage leads to mutations in mitochondrial DNA that are thought to contribute to cellular aging. The have found that estrogen decreases mitochondrial ROS production in cerebral blood vessels. This finding suggests that estrogen may effectively delay vascular aging; at the same time, it would be unable to reverse existing disease [93].

Studies of Huang and Kaley link some of these concepts to the adaptation to NO deficiency and the roles of estrogen and EDHF. In their studies two experimental approaches were used to decrease NO signaling: a genetic NOS 3 (eNOS) knockout model and the administration of a NO synthase inhibitor (L-NNA) in drinking water [94]. The principal findings were as follows: in NO deficiency, flow-induced dilation in skeletal muscle arterioles of male animals is primarily mediated by prostaglandins, whereas in those of females by EETs/EDHF [94]. In vessels of females, estrogens upregulate transcription factors (e.g. RXR gamma) and thereby increase CYP2C29 protein expression. This in turn, stimulates EETs/EDHF synthesis. In vessels of male $\mathrm{ER} \alpha \mathrm{KO}$ mice, $\mathrm{NO}$ production is low while the level of aromatase, an enzyme that converts androgens to estrogens is increased. The increased estrogen, via stimulation of ERbeta enhances the synthesis of EETs/EDHF [95-97].

Studies of Osol et al showed that in normotensive and hypertensive pregnancy there is an axial and circumferential remodeling of the uterine artery [98]. Using the rat nitric oxide synthase (NOS) inhibition (by L-NAME) model of gestational hypertension it was found that pregnancy is associated with significant circumferential (expansive) remodeling of the uterine arterial vasculature, as well as axial growth (elongation). These processes are required for normal uteroplacental perfusion and are largely regulated by local, rather than systemic factors. During hypertension induced by inhibition of nitric oxide synthase (NOS), there is almost complete attenuation of circumferential, but not axial remodeling in both large and small arteries. Interestingly, this effect is primarily due to the loss of NO signaling rather than the elevation in intravascular pressure [98].

\section{b) Microvascular Cell Signaling and Intercellular Communication. Intercellular Signaling in the Control of Vascular Resistance}

The control of tissue blood flow requires synchronous activity of smooth muscle cells (SMC) to coordinate vasodilatation and vasoconstriction along and among branches of vascular resistance networks. Endothelial cells (EC) are integral to coordinating such vasomotor responses. Local stimulation of arterioles or resistance arteries with acetylcholine (ACh) or bradykinin initiates vasodilation that travels rapidly along the vessel wall, reflecting hyperpolarization triggered by a local rise in $\left[\mathrm{Ca}^{2+}\right]_{\mathrm{i}}$ and the opening of $\mathrm{IK}_{\mathrm{Ca}}$ and $\mathrm{SK}_{\mathrm{Ca}}$ ion channels, along with the initiation of an endothelial $\mathrm{Ca}^{2+}$ wave [99]. In turn, hyperpolarization is conducted from cell to cell through gap junction channels that are expressed primarily between EC but also between SMC as well as between respective cell layers at myoendothelial junctions. Along the endothelium, gap junctions are composed of Cx37, Cx40 and 43, of which Cx40 appears crucial because loss of $\mathrm{Cx} 40$ impairs conducted vasodilation [100]. Remarkably, genetic replacement of $\mathrm{Cx} 40$ with $\mathrm{Cx} 45$ does not restore conducted responses, further indicating a key role for $\mathrm{Cx} 40$. The projection of EC through holes in the internal elastic lamina at myoendothelial junctions forms unique signaling microdomains with SMC [101]. Thus, changes in $\left[\mathrm{Ca}^{2+}\right]$ in the vicinity of EC projections can activate $\mathrm{IK}_{\mathrm{Ca}}$ channels 
that appear to be localized to these microdomains, providing a selective pathway for $\mathrm{K}^{+}$efflux to stimulate $\mathrm{Na} / \mathrm{K}$ ATPase and thereby contribute to endothelium dependent hyperpolarization independent of gap junctions [101]. In contrast, $\mathrm{SK}_{\mathrm{Ca}}$ channels expressed at EC borders can promote the spread of hyperpolarization into SMC through myoendothelial gap junctions.

An emerging picture is that the coordination of blood flow control at the organ level reflects the sum of coordinated responses within individual networks [102]. For example, pharmacological ligation of the $\alpha v \beta 3$ integrin receptor in downstream arterioles induces a series of events that begin an immediate increase in red blood cell velocity followed by dilation of proximal segments in a biphasic manner, ultimately resulting in an increase of blood flow into the arteriolar branch from which the stimulus arose [102]. One component of the dilation is blocked NOS inhibition and the second is blocked by inhibition of gap junctions, suggesting that both flow-induced and conducted vasodilation responses contribute to the integrated network response. A hallmark of tissue inflammation during sepsis is microvascular dysfunction, including the impairment of conducted responses [103]. Lipopolysaccharide (LPS, an initiating factor in sepsis) reduced electrical coupling between microvascular EC derived from mouse skeletal muscle in wild type (WT), $\mathrm{C} \times 37^{-/-}$, nonfunctional $\mathrm{Cx} 43^{\mathrm{G} 60 \mathrm{~S}}$, but not in $\mathrm{Cx} 40^{-/}$ EC. Underlying signaling events indicated that the reduction in electrical coupling occurred via PKA-specific serine dephosphorylation of $\mathrm{Cx} 40$ and was enhanced by hypoxia and reoxygenation.

Findings highlighted here provide novel insight with respect to how electrical and chemical signals within and between SMC and EC are initiated and travel along the vessel wall. Moreover, it is becoming increasingly apparent that these signaling events are modulated by subtle changes in the local milieu, hemodynamic forces and pathophysiological conditions.

\section{c) Intra and Intercellular Signaling Within the Microcirculation}

Although it has long been recognized that changes in the intracellular $\mathrm{Ca}^{2+}$ concentration are fundamental for cell signaling, the complex changes that occur within and between vascular cells and the integration necessary to regulate changes in artery diameter wall are still being unraveled. Vascular smooth muscle displays both spontaneous and evoked oscillations in intracellular $\left[\mathrm{Ca}^{2+}\right]$ giving rise to waves across the cells. However, observing these phenomena in isolation can only be used to infer links to muscle contraction/relaxation. By simultaneous measurement of both $\left[\mathrm{Ca}^{2+}\right]_{\mathrm{i}}$ and diameter change in pressurized cremasteric arterioles from the rat, Hill and colleagues demonstrated that while physiological increases in intraluminal pressure (up to $100 \mathrm{mmHg}$ ) link through the activation of ryanodine channels (but not $\mathrm{IP}_{3}$ channels) to an increase in frequency of $\mathrm{Ca}^{2+}$ oscillations and associated waves, they are not apparently modified by vascular myogenic contraction [104]. Developing these novel approaches will now hopefully lead on to definition of the links between $\left[\mathrm{Ca}^{2+}\right]$ and myogenic tone.

Oscillations in smooth muscle $\left[\mathrm{Ca}^{2+}\right]_{\mathrm{i}}$ do link to coordinated cycles of contraction/relaxation referred to as vasomotion, often but not always superimposed on myogenic contraction. While the physiological significance of vasomotion is still the subject of speculation, it does appear to be modulated by the endothelium. Beny and colleagues aimed to clarify the apparent confusion in the literature surrounding vasomotion, including its dependence (or not) on the endothelium [105]. Their data suggest that while the endothelium is not necessary for vasomotion, without it the constrictors like phenylephrine induce vasomotion over a lower and narrower concentration-range. Endothelium-derived relaxing products may then either induce or abolish vasomotion, so during non-oscillating contraction, relaxation originating from the endothelium can induce vasomotion. On the other hand, during vasomotion relaxation may induce transition to a non-oscillating state and slight contraction [105]. 
The mechanisms responsible for intercellular communication between endothelium and smooth muscle (and vice versa) were delineated by studies of the subject of Pohl [106] and Dora [107]. Combining $\mathrm{Ca}^{2+}$ measurements with molecular modification of specific connexins $(\mathrm{Cx})$, enabled Pohl's group to probe the hypothesis that the endothelial cell autacoid NO might specifically inhibit Cx37dependent gap-junctional communication [106]. This effect may be masked in endothelial monolayers by compensatory propagation through gap-junctions formed by other connexins, such as $\mathrm{Cx} 43$. These data highlight the importance of considering the specific connexins forming homo and heterocellular gap-junctions when linking such proteins to arterial function in both health and disease.

The complexity of heterocellular signaling in arterioles was addressed by studies of Dora et al in experiments assessing the link between intraluminal pressure and $\mathrm{Ca}^{2+}$ events in arteriolar endothelial cells [107]. Increasing luminal pressure increased spontaneous $\mathrm{Ca}^{2+}$ events in the smooth muscle, yet at the same time decreased spontaneous $\mathrm{Ca}^{2+}$ events in endothelial cells [107]. This apparent anomaly could not be explained by pressure-dependent changes in arteriolar membrane potential or diameter, but clearly depended on heterocellular gapjunctions, and highlighted the dynamic signaling interactions that occur in either direction between smooth muscle and endothelial cells. This raise the question: do reduced endothelial cell $\mathrm{Ca}^{2+}$ events underlie myogenic contraction in the microcirculation?

Borisova, Burdyga and colleagues provided the first observations of $\mathrm{Ca}^{2+}$ signaling in pericytes of precapillary sphincters in situ [108]. These data indicate a marked difference in the mechanisms controlling $\mathrm{Ca}^{2+}$ signaling and mechanical activity between smooth muscle and pericytes [108]. Also, they suggest the latter are more likely to act as local sphincters controlling capillary blood flow by responding to local factors.

Overall, these studies highlighted the necessity of using multiple technical approaches to unravel the mechanisms responsible for integrating signaling between and within the cells of the microcirculation.

\section{EXCHANGE AND CELL TRAFFICING IN MICORCIRCULATION}

\section{a) Will Lessons About Microvascular Permeability And Exchange Have To Be Re-Learnt?}

Between 1945 and 1980, advances in the analysis of biological transport processes, new experimental methods and many new observations led to more rigorous and more extensive investigations of the microcirculation and particularly microvascular exchange as summarized by C.C. Michel [109]. Recent advances in endothelial cell biology have moved many of these developments into the shadows. More seriously, the increasing dependence on internet searches of the scientific literature that are restricted to the past 30-40 years means that much valuable early work is in danger of being forgotten. Serious implications of this are not limited to the advances in knowledge of microvascular permeability and exchange but also concern the interpretation of widely used methods of assaying changes in microvascular permeability and the interpretation of plasma and tissue clearance curves. Charles Michel expressed concern that many investigators on molecules concerned with inflammation were assaying increases in vascular permeability using methods that gave ambiguous results. He criticized assays based on albumin fluxes through monolayer of cultured endothelium on the grounds that the albumin permeability of most monolayer was 100 to 10000 times greater than that of non-inflamed microvessels in situ. After briefly reviewing the theory underlying permeability coefficients (developed in the 1960's and 1970's), he also criticized the "Miles assay" that compared labeled serum albumin leakage from blood into areas of skin in vivo, arguing that its results were sensitive to changes in local hemodynamic. He cited experiments of Williams and Peck [110], who by measuring 
serum albumin clearance and local blood flow in the same tissue areas in a Miles assay, had shown how increased blood flow could amplify histamine induced albumin leakage. Using the increases in permeability coefficients induced by histamine [109], he demonstrated that the increases in albumin leakage, observed by Williams and Peck with increases in blood flow, were largely through increased convective albumin transport accompanying increased fluid filtration. He concluded that to measure changes in permeability, measure the permeability coefficients as only they relate fluxes of macromolecules to endothelial structure.

\section{b) The Endothelial Glycocalyx as a Barrier to Leukocyte-Endothelium Adhesion and Transvascular Exchange of Fluid}

The endothelial surface layer has been shown to serve as a barrier to leukocyte (WBC) adhesion to the endothelium (EC). When the EC is activated by the chemoattractant fMLP, glycans are shed that appear to shield ligands for WBCs such as ICAM-1. Study of Lipowsky et al [111] aimed to determine the extent to which glycans are shed in light of their contribution to the thickness of the layer and its ability to serve as a barrier to fluid exchange. To this end, shedding was delineated in post-capillary venules (rat mesentery) by measuring the intensity of the fluorescently labeled lectin BS-1, which binds preferentially to galactose, and infiltrates the glycocalyx. Superfusion with fMLP caused a $25 \%$ decrease in lectin binding within $30 \mathrm{~min}$ for arterioles, capillaries and venules. The apparent thickness of the layer was reduced by $20 \%$ during the shedding process, as evidenced by a decrease in thickness of the lectin stain from 0.9 to 0.7 microns. Changes in hydraulic conductivity of the layer were determined by analysis of the transit time of a bolus of fluorescent solutes (FITC) through the layer along the length of a venule, which revealed a $90 \%$ reduction. Thus, the structure of the EC glycocalyx may change dramatically to significantly affect WBC adhesion and transvascular exchange of fluid [111].

\section{c) Glycocalyx, Free Radicals and Aging}

Phagocytosing inflammatory cells (Polymorphonuclear Leukocytes, Macrophages and Monocytes) produce free radicals during the "oxygen burst" and are an example of how controlled free radical generation may be important in bacterial killing [112]. It has been suggested that free radicals derived from oxygen play an important role in the pathogenesis of damage induced by irradiation, inflammation and ischemia.Free radicals generated by metabolism, pollution, inflammation and/or stress are with increasing age increasing hydrogen peroxide which is long-lasting and can move in and out of cells. This is partly explained by decreasing catalase which occurs with increasing age but there is also and underperformance of other antioxidants. Normal older laboratory mice at an age of 15 months of a lifespan of 2 years will start to dysregulate cytokines, they form IL6, IL12 and later IL10 which will down-regulate the immune system [113]. NFkB is activated by hydrogen peroxide and just increasing their level of vitamin $\mathrm{E}$ will normalize their cytokine dysregulation. If vitamin $\mathrm{E}$ is removed in diet, dysregulation starts already after 5-6 months [113].

\section{d) The Role of Platelets in Hematopoietic Stem Cell Trafficking}

Beyond chronic inflammation and immune-cell interactions, vascular progenitor cells have recently gained appreciation through their participation in the pathogenesis of atherosclerosis and in arterial healing. While smooth muscle progenitor cells may favor plaque stability during advanced atherosclerosis, endothelial progenitor cells may promote plaque growth and vascularization, but their incorporation may also support the regeneration and recovery of the endothelial cell layer [114]. Likewise, bone marrow-derived progenitor cells have been implicated in vascular repair and remodeling involving the accumulation of smooth muscle and endothelial cells. However, mechanisms underlying their recruitment to sites of vascular injury have 
remained elusive. The work of Zernecke et al. [115] and Massberg et al. [116] has independently revealed that platelets provide critical signals that recruit CD34+ and Sca-1+ Lin- bone marrow-derived progenitor cells to sites of arterial denudation. The adhesion of bone marrow-derived circulating progenitor cells to matrix-adherent platelets and injured arteries required both P-selectin and GPIIb integrin on platelets, and was triggered through the receptor CXCR4 by the chemokine SDF-1, which is secreted and presented by activated platelets [115, 116]. The role of P-selectin interactions was confirmed by de Boer et al., who further demonstrated that fibrin-containing thrombi can support adhesion and migration of CD34+ cells to promote reendothelialization [117]. These findings uncover valuable clues refining the role of platelets in vascular homing of progenitor cells. It is conceivable that in the future improved imaging technology, namely two-photon laser scanning microscopy, will enable the visualization and quantification of subcellular structures in vital and functional murine arteries [118], to further unravel structurefunction relationships of the molecular determinants guiding progenitor cell trafficking in healthy and diseased arteries.

\section{NEW INSIGHTS OF LYMPHATIC FUNCTIONAL BIOLOGY}

\section{a) Forces in lymphatics}

The lymphatic system consists of a complex network of vessels whose main functions are 1) maintaining interstitial fluid balance by collecting fluid and solutes from the interstitial tissue to return them to the venous circulation; 2) trafficking immune cells from peripheral tissues to the lymph nodes, and 3) transporting lipid from the gut and periphery. Recent studies aim to integrate aspects of lymphatic physiology and biology, focusing on function and dysfunction rather than development, and to bridge the three main functions of the lymphatic system. Studies by Zawieja et al showed the importance of hydrodynamic forces, such as intraluminal pressure or shear stress, in modifying the tone of the smooth muscle cells on the lymphatic vessel wall, as well as the frequency and strength of the lymphatic contractile activity [119]. Their data provide compelling evidence for the effects of nitric oxide in regulating these effects, which points to direct regulation of smooth muscle by lymphatic endothelium via NOS pathways in response to shear stress [119]. Therefore, hydrodynamic forces are intrinsic regulators of lymphatic pump function. Adding to this, Negrini et al [120] demonstrated that adaptation of lymph flow to the required drainage tissue needs is performed not only in larger collecting ducts equipped with an efficient smooth muscle cell layer, but also through a certain degree of specialization even within the same hierarchic order of the initial lymphatic vessels originating directly from the interstitial tissue. In addition studies of Goldman et al built on earlier work to show that an intact interstitial tissue structure and the occurrence of a free interstitial tissue fluid flux is required for lymphangiogenesis, and conversely, that lymphangiogenesis alone is not sufficient to support an adequate lymph flow, in absence of the required interstitial tissue structure and fluid flow [121].

\section{b) Lipids in lymphatics}

Another emerging important topic is the lipid drainage function of the lymphatics. Recent data of Swartz et al (meeting abstract) show that lymphatic dysfunction is strongly correlated to lipid metabolism and deregulation. While lymphatic blockage leads to tissue fat accumulation and elevated serum cholesterol levels, sustained high blood cholesterol levels can also lead to lymphatic degeneration (meeting abstract). In the context of the immune cell trafficking, Shields et al showed how the drainage function of lymphatics may be coupled to the immune cell trafficking function by "autologous chemotaxis" [122]. Specifically, their study showed that dendritic cells can sense flow direction and thus use flow as a guiding cue towards draining lymphatics by secreting autologous chemokine that is then skewed by interstitial flow; the cells can then chemotact up that biased gradient [122]. Importantly, cells also receive chemotactic 
cues from lymphatic endothelium, specifically the lymphatic chemokine CCL21, and tumor cells, as well as immune cells can sense and respond to those cues [122]. In fact, these findings suggest that melanoma cells invade lymphatics in the peritumoral region by metastatic chemotaxis enhanced by upregulation of CCR7, the receptor for the CCL21 [122]. Based on all the above considerations and on the growing evidence of molecular responses to lymphatic vascular insufficiency in animal models, new perspectives may be envisaged for potential treatment of chronic lymphedema by dedicated pharmacotherapeutics, which would not only reduce tissue fluid accumulation, but also improve circulatory and immune function [123].

\section{HYPERTENSION AND HEART FAILURE. CONNECTING BASIC SCIENCE FINDINGS TO CLINICAL ISSUES}

\section{a) Small Arteries, Peripheral Vascular Resistance and Organ Damage in Hypertension.}

Recently many of the basic science findings were related to clinical findings as pointed out by Heagerty. It has been established that the hallmark of hypertension is an increase in peripheral vascular resistance Studies of small arteries have consistently demonstrated that there is a decrease in internal lumen diameter with an increase in media wall thickness but no change in crosssectional area and that the normal response to high blood pressure is termed eutrophic inward remodeling. This appears to occur as a result of the increase in wall stress, which a rise in blood pressure must bring about. One of the primary functional roles of small arteries is to regulate the flow of blood to downstream tissues. Much of this is accomplished by the myogenic response. However, when myogenic response is defective as is often observed in diabetes or in fully developed hypertension, there is an increase in wall stress and the compensatory mechanism for eutrophic remodeling is inadequate and is replaced by a growth response and hypertrophy of the vascular wall [124]. Studies most recently have demonstrated in a variety of tissues that the development of vascular wall hypertrophy is associated with target organ damage [124, 125]. In a series of studies recently completed, Haegerty at al demonstrated that effective management can reverse this process and restore normal vascular integrity [126].

\section{b) Pulse pressure and vascular damage. Differences in treatment modalities.}

S. Laurent focused on the damaging effect of local pulse pressure (PP), which has been well demonstrated on large arteries, and to a lesser extent on small arteries. Elevated PP can stimulate hypertrophy, remodeling, or rarefaction in the microcirculation, leading to increased resistance to blood flow $[127,128]$. Recent studies showed a close relationship between microvascular damage in brain and kidney and either pulse pressure or arterial stiffness, suggesting the connection between macro- and microvessels. Indeed, significant and independent relationships have been demonstrated between carotid stiffness and glomerular filtration rate (GFR) in patients with mild to moderate chronic kidney disease, between brachial pulse pressure and GFR in elderly patients with never-treated isolated systolic hypertension, and between arterial stiffness and cognitive impairment in elderly subjects attending a geriatric outpatient clinic. The damage of cerebral and renal small arteries can be explained on the basis of differential input impedance in the brain and kidney compared with other systemic vascular beds. The unique features of the kidney and brain are that they are continually and passively perfused at high-volume flow throughout systole and diastole. Their vascular resistance is very low, so that in comparison to other vascular beds, resistance is closer to input and characteristic impedance. Torrential flow and low resistance to flow in these organs expose small arterial vessels to the high-pressure fluctuations that exist in the carotid, vertebral, and renal arteries. Such fluctuations, measurable as central pulse pressure, increase 3- to 4-fold 
with age. Exposure of small vessels to highly pulsatile pressure and flow may explain microvascular damage and resulting renal insufficiency and intellectual deterioration.

A vicious cycle between small and large artery damage can be exemplified by the following: (a) increased wall-to-lumen ratio and rarefaction of small arteries are major factors for an increase in mean arterial blood pressure (BP); (b) the higher mean $\mathrm{BP}$ in turn increases large artery stiffness, through the loading of stiff components of the arterial wall at high BP levels; (c) the increased large artery stiffness is a major determinant of the increased PP, which in turn damages small arteries (and also favors the development of left ventricular hypertrophy, carotid intimamedia thickening and plaque rupture).

Thus antihypertensive treatments should break this vicious cycle to stop or reverse target organ damage. Importantly, not all pharmacological drugs are equal in this respect. Angiotensin converting enzyme (ACE) inhibitors, angiotensin II receptor antagonists, diuretics and calcium channel blockers have been repeatedly shown to reduce arterial stiffness, central BP and augmentation index, and small artery damage. By contrast, non-vasodilator beta-blockers have opposite effects, i.e. they increase central BP and augmentation index and do not reduce small artery damage as suggested by large clinical trials (LIFE, ASCOT studies).

\section{c) Endothelial Dysfunction in Human Hypertension}

It has been well established that the healthy endothelium plays a central role in cardiovascular control as summarized by $\mathrm{P}$. Poredoš [129-131]. Therefore, endothelial dysfunction (ED) may have a particularly significant role in the pathogenesis of atherosclerosis. As ED is a key underlying factor in the atherosclerotic process, markers of endothelial abnormalities have been sought, particularly those involving disturbed endothelium-dependent vasomotion. A large body of evidence indicates that ED is a characteristic of patients with essential hypertension and is characterized by impaired NO availability, determined by oxidative stress eliciting reduced NO bioavailability.
Further, an interaction between NO-system and endotelin-1 can participate in the pathogenesis of endothelial dysfunction. Although plasma levels of endothelin-1 do not seem to be increased in essential hypertension, it is worth noting that the vasoconstrictor activity has been found to be increased in parallel with diminished NO availability. In patients with essential hypertension endothelium-dependent vasodilation is impaired to acetylcholine and bradykinin, suggesting a generalized abnormality of endothelial vasodilator functions. It is presently unclear whether endothelial dysfunction is a primary abnormality or a consequence of the elevated blood pressure. Data in animal models are in favor of direct damage of the endothelial cells secondary to a prolonged increase of the hemodynamic load and shear stress. Further, the endothelial dysfunction observed in hypertension appears to be a consequence of high blood pressure since a variety of antihypertensive treatment normalizes these responses. However, in normotensive offsprings of hypertensive parents, an early alteration of endothelium-dependent vasodilation in the forearm was observed. Poredos et al also found impaired endothelial function in offsprings of parents with essential hypertension although their blood pressure was in normal range [132]. These data suggest a possibly relevant role of genetic mechanisms in the genesis of endothelial dysfunction in hypertension. Recent observations also favor the hypothesis that a dysfunctional endothelial NO-synthase gene polymorphism may be associated with essential hypertension, although this was not consistently observed in all populations.

\section{d) Microvascular Dysfunction in Human Hypertension}

There are growing evidences that impaired microcirculation plays an important role in the pathophysiology of arterial diseases. New data of Farkas at al support the role of microcirculation not only in the development of hypertensive target organ damage, but in the pathogenesis of hypertension, as well [133]. Laser Doppler 
flowmetry and capillarmicroscopy made it possible to assess microvascular endothelial function and microcirculatory structural changes, which can be observed in hypertension, but also in normotensive offspring of individuals with hypertension. These observations suggest that endothelial dysfunction and capillary rarefaction might play a role in the pathogenesis of primary hypertension. The microcirculation is a key site of increased vascular resistance, which is the major hemodynamic abnormality underlying elevated blood pressure in hypertension. Increase in central aortic stiffness, as measured by carotid-femoral pulse wave velocity, predicts cardiovascular mortality in patients with various cardiovascular diseases independent of other risk factors. It was previously shown, that relation between increased arterial stiffness and impaired microvascular function persisted in models that were adjusted for conventional risk factors, which indicates, that arterial stiffening is accompanied by microcirculatory structural or functional remodeling. A significant correlation between parameters of endothelial dysfunction, measured by laser Doppler flowmetry and arterial stiffness in hypertensive patients has been found [133].

\section{e) Current Practice and Future} Perspectives of Myocardial Stem Cell Therapy

Myocardial infarction became more frequent mainly in the developed countries in the past decades. Beside the pharmacological (thrombolysis, beta-blockers, ACE-inhibitors, antiplatelet- and lipid-lowering drugs, etc.) and interventional (percutaneous coronary intervention, intraaortic balloon pump, resynchronization therapy, left ventricular assist devices etc.) procedures the quality of life of patients and the morbidity and mortality data were improved as summarized by Edes. However, the development of heart failure following myocardial infarction is due primarily to the significant cell loss and left ventricular remodeling. In the last 5 years the myocardial stem cell therapy was introduced to human clinical phase to renew cardiomyocyte [134]. Edes described the general features of stem cells, why these cells are in the focus of the interest and their preclinical and clinical applications in myocardial infarction. Promising issues suggests, that intramyocardial implantation of autologous bone marrow derived stem cells become a new therapeutic modality in treatment of myocardial infarction [135]. Both experimental and human clinical studies executed in the last 5 years suggested that bone marrow derived cells may participate in the healing process after myocardial infarction. A number of small clinical trials indicated mild or moderate beneficial effect of intracoronary administration of bone marrow derived stem cells after myocardial infarction. Most of the studies used mononuclear cell fraction; due to the cellular heterogeneity of this cell population the type of the effective subpopulation was not known. These studies have demonstrated that the CD34+ subpopulation of bone marrow derived stem cells improves left ventricular function and viability after myocardial infarction [136]. It has been concluded, that the stem cell therapy could open new perspectives however, it is very important to remark, that this can be dangerous and can cause side effects because most molecular and cellular mechanisms of cell therapy are not clear at present.

\section{f) Growth and Function of Human Blood Vessels from Vascular Progenitor Cells (Vpc) In the Dog Heart with a Critical Stenosis of the Left Anterior Descending Coronary Artery.}

By the studies of Hintze and Anversa [137, 138] it has been previously identified and characterized adult cardiomyocyte progenitor cells from the human heart. Hintze at al aimed to isolate, expand and determine the potential of VPCs in the treatment of myocardial ischemia in the dog heart $[137,138]$. Human coronary vascular progenitor cells (hVPC) were isolated and transfected with green fluorescent protein (GFP). The cells were expanded and injected (106 cells) into the apical wall of the dog heart in the area of a critical stenosis in the hope of generating a collateral circulation. Dogs were immunosuppressed with cyclosporine. One month later hVPC derived blood vessels were evident by GFP fluorescence of smooth 
muscle and endothelial cells in the area of the LAD stenosis and consisted of blood vessels with diameters ranging from $50 \mathrm{um}$ to 1.5 $\mathrm{mm}$, some containing red blood cells. The human ALU antigen was evident by confocal microscopy indicating that these vessels were derived from hVPC. At one month after hVPC injection, upon total occlusion of the LAD coronary artery in the conscious dog, microsphere measured blood flow to the area of chronic ischemia was increased above that of normal levels. The vessels were also visualized during coronary angiography and three patterns were recognized during coronary occlusion: 1) filling of the LAD, which then dissipated slowly, 2) filling of what appeared to be a newly developed large epicardial $(1.5 \mathrm{~mm})$ coronary artery, and 3$)$ appearance of an epicardial halo creating a shadow on the epicardial surface. Thus, hVPC administration in a large animal heart results in the formation of functional large and small human coronary blood vessels which enhance blood flow in the area of a critical coronary stenosis and suggest that the use of VPCs has great potential in the treatment of myocardial ischemia especially where bypass surgery is not possible.

\section{NEW IMAGING AND OTHER TECHNIQUES IN MICROVASCULAR RESEARCH. FUNCTIONAL SIGNIFICANCE.}

At present, issues on new microscopy techniques are ranging from whole body recording at detailed levels, to large vessels, and finally to the smallest details including atomic force microscopy. Nevertheless, one should not forget about the "old" knowledge: the interplay between microscope and camera resolution, brightness, and field-of-view.

\section{a) Whole-body imaging with fluorescent proteins}

This technique is a powerful technology with many applications in small animals $[139,140]$. Brighter, red-shifted proteins can make whole-body imaging even more sensitive due to reduced absorption by tissues and less scatter. For example, a new protein called Katushka has been isolated that is the brightest known protein with emission at wavelengths longer than $620 \mathrm{~nm}$ [139, 140]. It offers potential for noninvasive whole-body macro imaging such as of tumor growth. For subcellular imaging, to observe cytoplasmic and nuclear dynamics in the living mouse, cancer cells were labeled in the nucleus with green fluorescent protein and in the cytoplasm with red fluorescent protein. Nuclear and cytoplasmic behavior of cancer cells in real time in blood vessels was imaged as they trafficked by various means or adhered to the vessel surface in the abdominal skin flap. During extravasation, real-time dual-color imaging showed that cytoplasmic processes of the cancer cells exited the vessels first, with nuclei following along the cytoplasmic projections. Both cytoplasm and nuclei underwent deformation during extravasation. Cancer cells trafficking in lymphatic vessels were also imaged. To noninvasively image cancer cell/stromal cell interaction in the tumor micro-environment as well as drug response at the cellular level in live animals in real time, a new imageable three-color animal model has been developed. The model consists of GFP-expressing mice transplanted with the dual-color cancer cells. With the dual-color cancer cells and a highly sensitive small animal imaging system, subcellular dynamics can now be observed in live mice in real time. Fluorescent proteins thus enable both macro and micro imaging technology and thereby provide the basis for the new field of in vivo cell biology [139, 140].

\section{b) Two-photon microscopy}

This is a relatively new microscopy technique that combines optical sectioning with a good depth of penetration [141]. The volume of actual excitation and, hence, the volume of emission and the resolution of the optics are determined by the excitation wavelength. Good resolution was obtained in large arteries up to a depth of 200microns. Using fluorochromes, such as quantum dots, specific structures may be labeled [118]. Quantum dots have high quantum yields, high photostability and a broad excitation/narrow emission spectrum, enabling long-term, 
multicolor imaging with a single wavelength excitation source. Studies may be performed ex-vivo in isolated, still functional blood vessels and in-vivo. Structures and alterations can be studied in large arteries (elastic versus muscular; common carotid and bifurcation) during (early) atherosclerosis in $\mathrm{ApoE}^{-/-}$and in control mice [142]: elastin layers, cell nuclei, collagen, apoptosis, endothelial glycocalyx, permeability of endothelium, atherogenesis, and angiogenesis of vasavasorum. Furthermore, neovascularization in tumors can be imaged.

\section{c) The Atomic Force Microscope (AFM)}

This is a high-resolution scanning-probe instrument which has become an important tool for cellular and molecular biophysics [143]. Although excellent in spatial resolution, it lacks the time resolution and functional specificities offered by fluorescence microscopic techniques. To exploit the advantages of both methods, we developed a spatially and temporally synchronized total internal reflection fluorescence and atomic force microscope system. This methodology was used to mechanically manipulate living pancreas carcinoma cells expressing recombinant eYFP-cytokeratin and to characterize the local viscoelasticity of targeted areas of their surface. From the force response recorded during the nanomechanical cycles, a complex behavior of the cell surface emerged. Depending on direction and magnitude of the force and the time scale of investigation, elastic, viscous and viscoelastic responses were observed. Exploring the molecular mechanisms behind these processes is key to our understanding the physiological processes at the cell periphery. AFM is becoming an increasingly useful tool for physiologists $[144,145]$. The technique has the resolution and sensitivity to allow topographical and mechanical measurements to be made in living cells at the micro-, nano- and picoscales. Combining AFM with fluorescence microscopy further enhances the utility of this instrument by permitting corresponding and simultaneous acquisition of fluorescence images pertaining to protein distribution and/or cell signaling events (e.g. intracellular
$\mathrm{Ca} 2+)$. AFM was successfully used to investigate the response of vascular smooth muscle cells to mechanical forces applied with an AFM probe conjugated with fibronectin. Cellular responses to the applied mechanical forces were also recorded with the AFM to reveal that mechanical force applied at the level of a single focal adhesion site would cause the cell to generate localized tension at that site, termed a micro-myogenic event.

\section{d). Measuring the total plasma homocystein in micro samples}

Hyperhomocysteinemia has been shown to be associated with cardiovascular diseases among others, it elicits endothelial dysfunction of arterioles. Thus measuring the level of homocystein (HCY) is of great importance. A protocol for measuring the total plasma homocystein (tHCY) concentration in very small samples using a selective, recombinant homocystein $\alpha, \gamma$-lyase (rHCYase) and a small portable fluorescence reader was recently described [146]. The rHCYase produces hydrogen sulfide $\left(\mathrm{H}_{2} \mathrm{~S}\right)$ from tHCY without interference from physiological concentrations of Cys or other plasma components. $\mathrm{H}_{2} \mathrm{~S}$ is determined through reactivity with N,N-dibutyl phenylene diamine (DBPDA), which leads to the formation of a fluorescent chromophore. Only $5 \mu 1$ of plasma/serum sample is required, which can be obtained from a finger prick, suggesting great potential for mass screening. The assay takes $\sim 20 \mathrm{~min}$.

\section{SUMMARY}

Although not complete, the above described cross section of avenues of today research in microcirculation, blood rheology and vascular biology - we believe - will lead us not only to a better understanding how circulation of organs are designed and regulated and affected by various conditions, but also will help us to design new modalities to temper pathophysiological alterations in microcirculation. 


\section{Acknowledgements:}

The Conference was supported generously

the National Office for Research and Technology, Albert Apponyi program, of

Hungary and the Hungarian Society for

Microcirculation and Vascular Biology, and

Andor Technology

Cellix Inc.

European Society of Cardiology -

CBSC working group 6

Hungarian Society of Hypertension

La Jolla Institute for Allergy and

Immunology

Kirin Pharma USA

PERIMED AB

Pfizer Inc. PhiloGene Inc.

Promocell Inc.

SERVIER Inc.

The British Pharmacological

Society

The Physiological Society

European Society for

Microcirculation

Hungarian Society for

Microcirculation and Vascular

Biology

Hungarian National Tourist Office 


\section{REFERENCES}

1 Zucker IH: Novel mechanisms of sympathetic regulation in chronic heart failure. Hypertension 2006;48:1005-1011.

2 Gao L, Wang WZ, Wang W, Zucker IH: Imbalance of angiotensin type 1 receptor and angiotensin ii type 2 receptor in the rostral ventrolateral medulla: Potential mechanism for sympathetic overactivity in heart failure. Hypertension 2008;52:708714.

3 Liu D, Gao L, Roy SK, Cornish KG, Zucker IH: Role of oxidant stress on at1 receptor expression in neurons of rabbits with heart failure and in cultured neurons. Circ Res 2008;103:186-193.

4 Gao L, Wang W, Zucker IH: Simvastatin inhibits central sympathetic outflow in heart failure by a nitric-oxide synthase mechanism. J Pharmacol Exp Ther 2008;326:278-285.

5 de Gasparo M, Catt KJ, Inagami T, Wright JW, Unger T: International union of pharmacology. Xxiii. The angiotensin ii receptors. Pharmacol Rev 2000;52:415-472.

6 Widdop RE, Vinh A, Henrion D, Jones ES: Vascular angiotensin at2 receptors in hypertension and ageing. Clin Exp Pharmacol Physiol 2008;35:386-390.

7 Sampson AK, Moritz KM, Jones ES, Flower RL, Widdop RE, Denton KM: Enhanced angiotensin ii type 2 receptor mechanisms mediate decreases in arterial pressure attributable to chronic low-dose angiotensin ii in female rats. Hypertension 2008;52:666-671. 
8 de Gasparo M: Angiotensin ii and nitric oxide interaction. Heart Fail Rev 2002;7:347-358.

9 Silvestre JS, Tamarat R, Senbonmatsu T, Icchiki T, Ebrahimian T, Iglarz M, Besnard S, Duriez M, Inagami T, Levy BI: Antiangiogenic effect of angiotensin ii type 2 receptor in ischemia-induced angiogenesis in mice hindlimb. Circ Res 2002;90:10721079.

10 Guilluy C, Rolli-Derkinderen M, Loufrani L, Bourge A, Henrion D, Sabourin L, Loirand G, Pacaud P: Ste20-related kinase slk phosphorylates ser188 of rhoa to induce vasodilation in response to angiotensin ii type 2 receptor activation. Circ Res $2008 ; 102: 1265-1274$.

11 Pinaud F, Bocquet A, Dumont O, Retailleau K, Baufreton C, Andriantsitohaina R, Loufrani L, Henrion D: Paradoxical role of angiotensin ii type 2 receptors in resistance arteries of old rats. Hypertension 2007;50:96-102.

12 Belin de Chantemele EJ, Vessieres E, Guihot AL, Toutain B, Maquignau M, Loufrani L, Henrion D: Type 2 diabetes severely impairs structural and functional adaptation of rat resistance arteries to chronic changes in blood flow. Cardiovasc Res 2009;81:788-796.

13 Pacher P, Batkai S, Kunos G: The endocannabinoid system as an emerging target of pharmacotherapy. Pharmacol Rev 2006;58:389-462. 
14 Lake KD, Compton DR, Varga K, Martin BR, Kunos G: Cannabinoid-induced hypotension and bradycardia in rats mediated by cb1-like cannabinoid receptors. $\mathrm{J}$ Pharmacol Exp Ther 1997;281:1030-1037.

15 Wagner JA, Varga K, Ellis EF, Rzigalinski BA, Martin BR, Kunos G: Activation of peripheral cb1 cannabinoid receptors in haemorrhagic shock. Nature 1997;390:518-521.

16 Varga K, Wagner JA, Bridgen DT, Kunos G: Platelet- and macrophage-derived endogenous cannabinoids are involved in endotoxin-induced hypotension. FASEB J 1998;12:1035-1044.

17 Batkai S, Pacher P, Osei-Hyiaman D, Radaeva S, Liu J, Harvey-White J, Offertaler L, Mackie K, Rudd MA, Bukoski RD, Kunos G: Endocannabinoids acting at cannabinoid-1 receptors regulate cardiovascular function in hypertension. Circulation 2004;110:1996-2002.

18 Rattigan S, Bussey CT, Ross RM, Richards SM: Obesity, insulin resistance, and capillary recruitment. Microcirculation 2007;14:299-309.

19 Ellmerer M, Hamilton-Wessler M, Kim SP, Huecking K, Kirkman E, Chiu J, Richey J, Bergman RN: Reduced access to insulin-sensitive tissues in dogs with obesity secondary to increased fat intake. Diabetes 2006;55:1769-1775.

20 Bakker W, Sipkema P, Stehouwer CD, Serne EH, Smulders YM, van Hinsbergh VW, Eringa EC: Protein kinase c theta activation induces insulin-mediated constriction of muscle resistance arteries. Diabetes 2008;57:706-713. 
21 Doronzo G, Russo I, Mattiello L, Riganti C, Anfossi G, Trovati M: Insulin activates hypoxia-inducible factor-1alpha in human and rat vascular smooth muscle cells via phosphatidylinositol-3 kinase and mitogen-activated protein kinase pathways: Impairment in insulin resistance owing to defects in insulin signalling. Diabetologia 2006;49:1049-1063.

22 Hodnett BL, Dearman JA, Carter CB, Hester RL: Attenuated pgi2 synthesis in obese zucker rats. Am J Physiol Regul Integr Comp Physiol 2009;296:R715-721.

23 Hodnett BL, Xiang L, Dearman JA, Carter CB, Hester RL: K(atp)-mediated vasodilation is impaired in obese zucker rats. Microcirculation 2008;15:485-494.

24 Xiang L, Dearman J, Abram SR, Carter C, Hester RL: Insulin resistance and impaired functional vasodilation in obese zucker rats. Am J Physiol Heart Circ Physiol 2008;294:H1658-1666.

25 Schreihofer AM, Mandel DA, Mobley SC, Stepp DW: Impairment of sympathetic baroreceptor reflexes in obese zucker rats. Am J Physiol Heart Circ Physiol 2007;293:H2543-2549.

26 Osmond JM, Mintz JD, Dalton B, Stepp DW: Obesity increases blood pressure, cerebral vascular remodeling, and severity of stroke in the zucker rat. Hypertension 2009;53:381-386.

27 Van Teeffelen JW, Brands J, Stroes ES, Vink H: Endothelial glycocalyx: Sweet shield of blood vessels. Trends Cardiovasc Med 2007;17:101-105. 
28 Muller G, Meissner S, Walther J, Cuevas M, Koch E, Morawietz H: Analysis of murine vascular function in vivo by optical coherence tomography in response to highfat diet. Horm Metab Res 2009

29 Eichhorn B, Muller G, Leuner A, Sawamura T, Ravens U, Morawietz H: Impaired vascular function in small resistance arteries of lox-1 overexpressing mice on high-fat diet. Cardiovasc Res 2009

30 Clough G, Turzyniecka M, Walter L, Krentz A, Wild S, Chipperfield A, Gamble J, Byrne C: Muscle microvascular dysfunction in central obesity is related to muscle insulin insensitivity but is not reversed by high-dose statin treatment. Diabetes 2009

31 Erdei N, Bagi Z, Edes I, Kaley G, Koller A: H2o2 increases production of constrictor prostaglandins in smooth muscle leading to enhanced arteriolar tone in type 2 diabetic mice. Am J Physiol Heart Circ Physiol 2007;292:H649-656.

32 Bagi Z, Erdei N, Papp Z, Edes I, Koller A: Up-regulation of vascular cyclooxygenase-2 in diabetes mellitus. Pharmacol Rep 2006;58 Suppl:52-56.

33 Szerafin T, Erdei N, Fulop T, Pasztor ET, Edes I, Koller A, Bagi Z: Increased cyclooxygenase- 2 expression and prostaglandin-mediated dilation in coronary arterioles of patients with diabetes mellitus. Circ Res 2006;99:e12-17.

34 Fulop T, Jebelovszki E, Erdei N, Szerafin T, Forster T, Edes I, Koller A, Bagi Z: Adaptation of vasomotor function of human coronary arterioles to the simultaneous 
presence of obesity and hypertension. Arterioscler Thromb Vasc Biol 2007;27:23482354.

35 Jebelovszki E, Kiraly C, Erdei N, Feher A, Pasztor ET, Rutkai I, Forster T, Edes I, Koller A, Bagi Z: High-fat diet-induced obesity leads to increased no sensitivity of rat coronary arterioles: Role of soluble guanylate cyclase activation. Am J Physiol Heart Circ Physiol 2008;294:H2558-2564.

36 Martini J, Carpentier B, Chavez Negrete A, Cabrales P, Tsai AG, Intaglietta M: Beneficial effects due to increasing blood and plasma viscosity. Clin Hemorheol Microcirc 2006;35:51-57.

37 Salazar Vazquez BY, Salazar Vazquez MA, Venzor VC, Negrete AC, Cabrales P, Diaz JS, Intaglietta M: Increased hematocrit and reduced blood pressure following control of glycemia in diabetes. Clin Hemorheol Microcirc 2008;38:57-64.

38 Intaglietta M, Cabrales P, Tsai AG: Microvascular perspective of oxygencarrying and -noncarrying blood substitutes. Annu Rev Biomed Eng 2006;8:289-321.

39 Reneman RS, Arts T, Hoeks AP: Wall shear stress--an important determinant of endothelial cell function and structure--in the arterial system in vivo. Discrepancies with theory. J Vasc Res 2006;43:251-269.

40 Reneman RS, Hoeks AP: Wall shear stress as measured in vivo: Consequences for the design of the arterial system. Med Biol Eng Comput 2008;46:499-507. 
41 Koller A, Kaley G: Endothelial regulation of wall shear stress and blood flow in skeletal muscle microcirculation. Am J Physiol 1991;260:H862-868.

42 Racz A, Veresh Z, Erdei N, Bagi Z, Koller A: Thromboxane a(2) contributes to the mediation of flow-induced responses of skeletal muscle venules: Role of cyclooxygenases 1 and 2. J Vasc Res 2009;46:397-405.

43 Koller A, Sun D, Huang A, Kaley G: Corelease of nitric oxide and prostaglandins mediates flow-dependent dilation of rat gracilis muscle arterioles. Am J Physiol 1994;267:H326-332.

44 Koller A, Bagi Z: Nitric oxide and h2o2 contribute to reactive dilation of isolated coronary arterioles. Am J Physiol Heart Circ Physiol 2004;287:H2461-2467.

45 Bryan RM, Jr., Marrelli SP, Steenberg ML, Schildmeyer LA, Johnson TD: Effects of luminal shear stress on cerebral arteries and arterioles. Am J Physiol Heart Circ Physiol 2001;280:H2011-2022.

46 van den Berg BM, Spaan JA, Vink H: Impaired glycocalyx barrier properties contribute to enhanced intimal low-density lipoprotein accumulation at the carotid artery bifurcation in mice. Pflugers Arch 2009;457:1199-1206.

47 Broekhuizen LN, Mooij HL, Kastelein JJ, Stroes ES, Vink H, Nieuwdorp M: Endothelial glycocalyx as potential diagnostic and therapeutic target in cardiovascular disease. Curr Opin Lipidol 2009;20:57-62. 
48 Brown MD, Hudlicka O: Modulation of physiological angiogenesis in skeletal muscle by mechanical forces: Involvement of vegf and metalloproteinases. Angiogenesis 2003;6:1-14.

49 Williams JL, Cartland D, Hussain A, Egginton S: A differential role for nitric oxide in two forms of physiological angiogenesis in mouse. J Physiol 2006;570:445454.

50 Bevan HS, van den Akker NM, Qiu Y, Polman JA, Foster RR, Yem J, Nishikawa A, Satchell SC, Harper SJ, Gittenberger-de Groot AC, Bates DO: The alternatively spliced anti-angiogenic family of vegf isoforms vegfxxxb in human kidney development. Nephron Physiol 2008;110:p57-67.

51 Harper SJ, Bates DO: Vegf-a splicing: The key to anti-angiogenic therapeutics? Nat Rev Cancer 2008;8:880-887.

52 Nowak DG, Woolard J, Amin EM, Konopatskaya O, Saleem MA, Churchill AJ, Ladomery MR, Harper SJ, Bates DO: Expression of pro- and anti-angiogenic isoforms of vegf is differentially regulated by splicing and growth factors. J Cell Sci 2008;121:3487-3495.

53 Bott RC, Clopton DT, Cupp AS: A proposed role for vegf isoforms in sexspecific vasculature development in the gonad. Reprod Domest Anim 2008;43 Suppl 2:310-316.

54 Hofer E, Schweighofer B: Signal transduction induced in endothelial cells by growth factor receptors involved in angiogenesis. Thromb Haemost 2007;97:355-363. 
55 Clifford PS, Hellsten Y: Vasodilatory mechanisms in contracting skeletal muscle. J Appl Physiol 2004;97:393-403.

56 Mortensen SP, Gonzalez-Alonso J, Damsgaard R, Saltin B, Hellsten Y: Inhibition of nitric oxide and prostaglandins, but not endothelial-derived hyperpolarizing factors, reduces blood flow and aerobic energy turnover in the exercising human leg. J Physiol 2007;581:853-861.

57 Yang AL, Su CT, Lin KL, Chao JI, You HP, Lee SD: Exercise training improves insulin-induced and insulin-like growth factor-1-induced vasorelaxation in rat aortas. Life Sci 2006;79:2017-2021.

58 Prior BM, Yang HT, Terjung RL: What makes vessels grow with exercise training? J Appl Physiol 2004;97:1119-1128.

59 Lloyd PG, Yang HT, Terjung RL: Arteriogenesis and angiogenesis in rat ischemic hindlimb: Role of nitric oxide. Am J Physiol Heart Circ Physiol 2001;281:H2528-2538.

60 Duncker DJ, Merkus D: Exercise hyperaemia in the heart: The search for the dilator mechanism. J Physiol 2007;583:847-854.

61 Toyota E, Ogasawara Y, Hiramatsu O, Tachibana H, Kajiya F, Yamamori S, Chilian WM: Dynamics of flow velocities in endocardial and epicardial coronary arterioles

10.1152/ajpheart.01103.2003. Am J Physiol Heart Circ Physiol 2005;288:H1598-1603. 
62 de Beer VJ, Sorop O, Pijnappels DA, Dekkers DH, Boomsma F, Lamers JMJ, Duncker DJ, Merkus D: Integrative control of coronary resistance vessel tone by endothelin and angiotensin ii is altered in swine with a recent myocardial infarction 10.1152/ajpheart.01163.2007. Am J Physiol Heart Circ Physiol 2008;294:H2069-2077.

63 Duncker DJ, Bache RJ: Regulation of coronary blood flow during exercise 10.1152/physrev.00045.2006. Physiol Rev 2008;88:1009-1086.

64 Duncker DJ, Merkus D: Exercise hyperaemia in the heart: The search for the dilator mechanism

10.1113/jphysiol.2007.135525. J Physiol 2007;583:847-854.

65 Duncker DJ, Oei HH, Hu F, Stubenitsky R, Verdouw PD: Role of katp+ channels in regulation of systemic, pulmonary, and coronary vasomotor tone in exercising swine. Am J Physiol Heart Circ Physiol 2001;280:H22-33.

66 Gollasch M, Ried C, Bychkov R, Luft FC, Haller H: K+ currents in human coronary artery vascular smooth muscle cells. Circ Res 1996;78:676-688.

67 Gutterman DD, Miura H, Liu Y: Redox modulation of vascular tone: Focus of potassium channel mechanisms of dilation

10.1161/01.Atv.0000158497.09626.3b. Arterioscler Thromb Vasc Biol 2005;25:671678.

68 Merkus D, Sorop O, Houweling B, Hoogteijling BA, Duncker DJ: Kca+ channels contribute to exercise-induced coronary vasodilation in swine 10.1152/ajpheart.00315.2006. Am J Physiol Heart Circ Physiol 2006;291:H2090-2097. 
69 Rogers PA, Dick GM, Knudson JD, Focardi M, Bratz IN, Swafford AN, Jr., Saitoh S-i, Tune JD, Chilian WM: H2o2-induced redox-sensitive coronary vasodilation is mediated by 4-aminopyridine-sensitive $\mathrm{k}+$ channels

10.1152/ajpheart.00172.2006. Am J Physiol Heart Circ Physiol 2006;291:H2473-2482.

70 Merkus D, Duncker DJ, Chilian WM: Metabolic regulation of coronary vascular tone: Role of endothelin-1

10.1152/ajpheart.00223.2002. Am J Physiol Heart Circ Physiol 2002;283:H1915-1921.

71 Merkus D, Brzezinska AK, Zhang C, Saito S, Chilian WM: Cardiac myocytes control release of endothelin-1 in coronary vasculature

10.1152/ajpheart.00522.2003. Am J Physiol Heart Circ Physiol 2005;288:H2088-2092.

72 Saitoh S-i, Kiyooka T, Rocic P, Rogers PA, Zhang C, Swafford A, Dick GM, Viswanathan C, Park Y, Chilian WM: Redox-dependent coronary metabolic dilation 10.1152/ajpheart.00436.2007. Am J Physiol Heart Circ Physiol 2007;293:H3720-3725.

73 Saitoh S-i, Zhang C, Tune JD, Potter B, Kiyooka T, Rogers PA, Knudson JD, M. Dick G, Swafford A, Chilian WM: Hydrogen peroxide: A feed-forward dilator that couples myocardial metabolism to coronary blood flow

10.1161/01.Atv.0000249408.55796.Da. Arterioscler Thromb Vasc Biol 2006;26:26142621.

74 Duncker DJ, Stubenitsky R, Verdouw PD: Role of adenosine in the regulation of coronary blood flow in swine at rest and during treadmill exercise. Am J Physiol 1998;275:H1663-1672. 
75 Merkus D, Haitsma DB, Fung T-Y, Assen YJ, Verdouw PD, Duncker DJ: Coronary blood flow regulation in exercising swine involves parallel rather than redundant vasodilator pathways

10.1152/ajpheart.00916.2002. Am J Physiol Heart Circ Physiol 2003;285:H424-433.

76 Merkus D, Houweling B, Zarbanoui A, Duncker DJ: Interaction between prostanoids and nitric oxide in regulation of systemic, pulmonary, and coronary vascular tone in exercising swine. Am J Physiol Heart Circ Physiol 2004;286:H11141123.

77 Merkus D, Sorop O, Houweling B, Boomsma F, van den Meiracker AH, Duncker DJ: No and prostanoids blunt endothelin-mediated coronary vasoconstrictor influence in exercising swine

10.1152/ajpheart.01109.2005. Am J Physiol Heart Circ Physiol 2006;291:H2075-2081.

78 Wiley KE, Davenport AP: Nitric oxide-mediated modulation of the endothelin1 signalling pathway in the human cardiovascular system. $\mathrm{Br} \mathrm{J}$ Pharmacol 2001;132:213-220.

79 Haitsma DB, Bac D, Raja N, Boomsma F, Verdouw PD, Duncker DJ: Minimal impairment of myocardial blood flow responses to exercise in the remodeled left ventricle early after myocardial infarction, despite significant hemodynamic and neurohumoral alterations

10.1016/s0008-6363(01)00426-6. Cardiovasc Res 2001;52:417-428. 
80 Duncker DJ, Stubenitsky R, Verdouw PD: Autonomic control of vasomotion in the porcine coronary circulation during treadmill exercise : Evidence for feed-forward ß-adrenergic control. Circ Res 1998;82:1312-1322.

81 Merkus D, Haitsma DB, Sorop O, Boomsma F, de Beer VJ, Lamers JMJ, Verdouw PD, Duncker DJ: Coronary vasoconstrictor influence of angiotensin ii is reduced in remodeled myocardium after myocardial infarction 10.1152/ajpheart.00861.2005. Am J Physiol Heart Circ Physiol 2006;291:H2082-2089.

82 Jones CJ, Kuo L, Davis MJ, Chilian WM: Distribution and control of coronary microvascular resistance. Adv Exp Med Biol 1993;346:181-188.

83 Laughlin MH, Korthuis RJ, Duncker DJ, Bache RJ: Control of blood flow to cardiac and skeletal muscle during exercise. Chapter 16. New York, American Physiological Society and Oxford University Press, 1996.

84 Laughlin MH, Cook J, Tremble R, Ingram D, Colleran PN, Turk JR: Exercise training produces nonuniform increases in arteriolar density of rat soleus and gastrocnemius muscle. Microcirculation 2006;13:175-186.

85 Laughlin MH, Korthuis RJ, Sexton WL, Armstrong RB: Regional muscle blood flow capacity and exercise hyperemia in high intensity trained rats. Journal of Applied Physiology 1988;64:2420-2427.

86 Laughlin MH, Woodman CR, Schrage WG, Gute D, Price EM: Interval sprint training enhances endothelial function and enos content in some arteries that perfuse white gastrocnemius muscle. J Appl Physiol 2004;96:233-244. 
87 McAllister RM, Jasperse JL, Laughlin MH: Nonuniform effects of endurance exercise training on vasodilation in rat skeletal muscle. J Appl Physiol 2005;98:753761.

88 Binder KW, Murfee WL, Song J, Laughlin MH, Price RJ: Computational network model prediction of hemodynamic alterations due to arteriolar remodeling in interval sprint trained skeletal muscle. Microcirculation 2007;14:181 - 192.

89 Gute D, Laughlin MH, Amann JF: Regional changes in capillary supply in skeletal muscle of interval-sprint and low intensity, endurance trained rats. Microcirculation 1994;1:183-193.

90 Gute D, Fraga C, Laughlin MH, Amann JF: Regional changes in capillary supply in skeletal muscle of high-intensity endurance-trained rats. Journal of Applied Physiology 1996;81:619-626.

91 Sexton WL, Korthuis RJ, Laughlin MH: High intensity exercise training increases vascular transport capacity of rat hindquarters. American Journal of Physiology, Heart and Circulatory Physiology 1988;254:H274-H278.

92 Sexton WL, Laughlin MH: Influence of endurance exercise training on distribution of vascular adaptations in rat skeletal muscle. American Journal of Physiology 1994;266:H483-H490.

93 Duckles SP, Krause DN, Stirone C, Procaccio V: Estrogen and mitochondria: A new paradigm for vascular protection? Mol Interv 2006;6:26-35. 
94 Huang A, Wu Y, Sun D, Koller A, Kaley G: Effect of estrogen on flow-induced dilation in no deficiency: Role of prostaglandins and edhf. J Appl Physiol 2001;91:2561-2566.

95 Huang A, Kaley G: Gender-specific regulation of cardiovascular function: Estrogen as key player. Microcirculation 2004;11:9-38.

96 Huang A, Sun D, Wu Z, Yan C, Carroll MA, Jiang H, Falck JR, Kaley G: Estrogen elicits cytochrome p450--mediated flow-induced dilation of arterioles in no deficiency: Role of pi3k-akt phosphorylation in genomic regulation. Circ Res 2004;94:245-252.

97 Serova LI, Maharjan S, Huang A, Sun D, Kaley G, Sabban EL: Response of tyrosine hydroxylase and gtp cyclohydrolase $\mathrm{i}$ gene expression to estrogen in brain catecholaminergic regions varies with mode of administration. Brain Res 2004;1015:18.

98 Osol G, Barron C, Gokina N, Mandala M: Inhibition of nitric oxide synthases abrogates pregnancy-induced uterine vascular expansive remodeling. J Vasc Res 2009;46:478-486.

99 Domeier TL, Segal SS: Electromechanical and pharmacomechanical signalling pathways for conducted vasodilatation along endothelium of hamster feed arteries. J Physiol 2007;579:175-186. 
100 Wolfle SE, Schmidt VJ, Hoepfl B, Gebert A, Alcolea S, Gros D, de Wit C: Connexin45 cannot replace the function of connexin40 in conducting endotheliumdependent dilations along arterioles. Circ Res 2007;101:1292-1299.

101 Dora KA, Gallagher NT, McNeish A, Garland CJ: Modulation of endothelial cell kca3.1 channels during endothelium-derived hyperpolarizing factor signaling in mesenteric resistance arteries. Circ Res 2008;102:1247-1255.

102 Frame MD, Rivers RJ, Altland O, Cameron S: Mechanisms initiating integrinstimulated flow recruitment in arteriolar networks. J Appl Physiol 2007;102:2279-2287.

103 Lidington D, Ouellette Y, Li F, Tyml K: Conducted vasoconstriction is reduced in a mouse model of sepsis. J Vasc Res 2003;40:149-158.

104 Raina H, Ella SR, Hill MA: Decreased activity of the smooth muscle na+/ca2+ exchanger impairs arteriolar myogenic reactivity. J Physiol 2008;586:1669-1681.

105 Seppey D, Sauser R, Koenigsberger M, Beny JL, Meister JJ: Does the endothelium abolish or promote arterial vasomotion in rat mesenteric arteries? Explanations for the seemingly contradictory effects. J Vasc Res 2008;45:416-426.

106 Kameritsch P, Khandoga N, Nagel W, Hundhausen C, Lidington D, Pohl U: Nitric oxide specifically reduces the permeability of cx37-containing gap junctions to small molecules. J Cell Physiol 2005;203:233-242. 
107 Kansui Y, Garland CJ, Dora KA: Enhanced spontaneous ca2+ events in endothelial cells reflect signalling through myoendothelial gap junctions in pressurized mesenteric arteries. Cell Calcium 2008;44:135-146.

108 Borisova L, Shmygol A, Wray S, Burdyga T: Evidence that a ca2+ sparks/stocs coupling mechanism is responsible for the inhibitory effect of caffeine on electromechanical coupling in guinea pig ureteric smooth muscle. Cell Calcium 2007;42:303311.

109 Michel CC, Kendall S: Differing effects of histamine and serotonin on microvascular permeability in anaesthetized rats. J Physiol 1997;501 ( Pt 3):657-662.

110 Williams TJ, Peck MJ: Role of prostaglandin-mediated vasodilatation in inflammation. Nature 1977;270:530-532.

111 Mulivor AW, Lipowsky HH: Inflammation- and ischemia-induced shedding of venular glycocalyx. Am J Physiol Heart Circ Physiol 2004;286:H1672-1680.

112 Lehr HA, Arfors KE: Mechanisms of tissue damage by leukocytes. Curr Opin Hematol 1994;1:92-99.

113 Poynter ME, Daynes RA: Peroxisome proliferator-activated receptor alpha activation modulates cellular redox status, represses nuclear factor-kappab signaling, and reduces inflammatory cytokine production in aging. J Biol Chem 1998;273:3283332841. 
114 Weber C, Zernecke A, Libby P: The multifaceted contributions of leukocyte subsets to atherosclerosis: Lessons from mouse models. Nat Rev Immunol 2008;8:802815.

115 Zernecke A, Schober A, Bot I, von Hundelshausen P, Liehn EA, Mopps B, Mericskay M, Gierschik P, Biessen EA, Weber C: Sdf-1alpha/cxcr4 axis is instrumental in neointimal hyperplasia and recruitment of smooth muscle progenitor cells. Circ Res 2005;96:784-791.

116 Massberg S, Konrad I, Schurzinger K, Lorenz M, Schneider S, Zohlnhoefer D, Hoppe K, Schiemann M, Kennerknecht E, Sauer S, Schulz C, Kerstan S, Rudelius M, Seidl S, Sorge F, Langer H, Peluso M, Goyal P, Vestweber D, Emambokus NR, Busch DH, Frampton J, Gawaz M: Platelets secrete stromal cell-derived factor 1alpha and recruit bone marrow-derived progenitor cells to arterial thrombi in vivo. J Exp Med 2006;203:1221-1233.

117 de Boer HC, Verseyden C, Ulfman LH, Zwaginga JJ, Bot I, Biessen EA, Rabelink TJ, van Zonneveld AJ: Fibrin and activated platelets cooperatively guide stem cells to a vascular injury and promote differentiation towards an endothelial cell phenotype. Arterioscler Thromb Vasc Biol 2006;26:1653-1659.

118 Megens RT, Reitsma S, Schiffers PH, Hilgers RH, De Mey JG, Slaaf DW, oude Egbrink MG, van Zandvoort MA: Two-photon microscopy of vital murine elastic and muscular arteries. Combined structural and functional imaging with subcellular resolution. J Vasc Res 2007;44:87-98. 
119 Muthuchamy M, Zawieja D: Molecular regulation of lymphatic contractility. Ann N Y Acad Sci 2008;1131:89-99.

120 Moriondo A, Bianchin F, Marcozzi C, Negrini D: Kinetics of fluid flux in the rat diaphragmatic submesothelial lymphatic lacunae. Am J Physiol Heart Circ Physiol 2008;295:H1182-H1190.

121 Uzarski J, Drelles MB, Gibbs SE, Ongstad EL, Goral JC, McKeown KK, Raehl AM, Roberts MA, Pytowski B, Smith MR, Goldman J: The resolution of lymphedema by interstitial flow in the mouse tail skin. Am J Physiol Heart Circ Physiol 2008;294:H1326-1334.

122 Shields JD, Emmett MS, Dunn DB, Joory KD, Sage LM, Rigby H, Mortimer PS, Orlando A, Levick JR, Bates DO: Chemokine-mediated migration of melanoma cells towards lymphatics--a mechanism contributing to metastasis. Oncogene 2007;26:2997-3005.

123 Nakamura K, Rockson SG: Molecular targets for therapeutic lymphangiogenesis in lymphatic dysfunction and disease. Lymphat Res Biol 2008;6:181-189.

124 Khavandi K, Greenstein AS, Sonoyama K, Withers S, Price A, Malik RA, Heagerty AM: Myogenic tone and small artery remodelling: Insight into diabetic nephropathy. Nephrol Dial Transplant 2009;24:361-369. 
125 Paisley AN, Izzard AS, Gemmell I, Cruickshank K, Trainer PJ, Heagerty AM: Small vessel remodeling and impaired endothelial-dependent dilatation in subcutaneous resistance arteries from patients with acromegaly. J Clin Endocrinol Metab 2009

126 Agabiti-Rosei E, Heagerty AM, Rizzoni D: Effects of antihypertensive treatment on small artery remodelling. J Hypertens 2009

127 Laurent S, Boutouyrie P: Arterial stiffness: A new surrogate end point for cardiovascular disease? J Nephrol 2007;20 Suppl 12:S45-50.

128 Laurent S, Boutouyrie P: Recent advances in arterial stiffness and wave reflection in human hypertension. Hypertension 2007;49:1202-1206.

129 Poredos P: Endothelial dysfunction and cardiovascular disease. Pathophysiol Haemost Thromb 2002;32:274-277.

130 Poredos P: Endothelial dysfunction in the pathogenesis of atherosclerosis. Int Angiol 2002;21:109-116.

131 Poredos P: Intima-media thickness: Indicator of cardiovascular risk and measure of the extent of atherosclerosis. Vasc Med 2004;9:46-54.

132 Zizek B, Poredos P, Videcnik V: Endothelial dysfunction in hypertensive patients and in normotensive offspring of subjects with essential hypertension. Heart 2001;85:215-217. 
133 Farkas K, Kolossvary E, Jarai Z, Nemcsik J, Farsang C: Non-invasive assessment of microvascular endothelial function by laser doppler flowmetry in patients with essential hypertension. Atherosclerosis 2004;173:97-102.

134 Nyolczas N, Gyongyosi M, Beran G, Dettke M, Graf S, Sochor H, Christ G, Edes I, Balogh L, Krause KT, Jaquet K, Kuck KH, Benedek I, Hintea T, Kiss R, Preda I, Kotevski V, Pejkov H, Dudek D, Heba G, Sylven C, Charwat S, Jacob R, Maurer G, Lang I, Glogar D: Design and rationale for the myocardial stem cell administration after acute myocardial infarction (mystar) study: A multicenter, prospective, randomized, single-blind trial comparing early and late intracoronary or combined (percutaneous intramyocardial and intracoronary) administration of nonselected autologous bone marrow cells to patients after acute myocardial infarction. Am Heart J 2007;153:212 e211-217.

135 Gyongyosi M, Lang I, Dettke M, Beran G, Graf S, Sochor H, Nyolczas N, Charwat S, Hemetsberger R, Christ G, Edes I, Balogh L, Krause KT, Jaquet K, Kuck KH, Benedek I, Hintea T, Kiss R, Preda I, Kotevski V, Pejkov H, Zamini S, Khorsand A, Sodeck G, Kaider A, Maurer G, Glogar D: Combined delivery approach of bone marrow mononuclear stem cells early and late after myocardial infarction: The mystar prospective, randomized study. Nat Clin Pract Cardiovasc Med 2009;6:70-81.

136 Balogh L, Czuriga I, Hunyadi J, Galuska L, Kristof E, Edes I: [effects of autologous bone marrow derived cd34+ stem cells on the left ventricular function following myocardial infarction]. Orv Hetil 2007;148:243-249. 
137 Gonzalez A, Rota M, Nurzynska D, Misao Y, Tillmanns J, Ojaimi C, PadinIruegas ME, Muller P, Esposito G, Bearzi C, Vitale S, Dawn B, Sanganalmath SK, Baker M, Hintze TH, Bolli R, Urbanek K, Hosoda T, Anversa P, Kajstura J, Leri A: Activation of cardiac progenitor cells reverses the failing heart senescent phenotype and prolongs lifespan. Circ Res 2008;102:597-606.

138 Tillmanns J, Rota M, Hosoda T, Misao Y, Esposito G, Gonzalez A, Vitale S, Parolin C, Yasuzawa-Amano S, Muraski J, De Angelis A, Lecapitaine N, Siggins RW, Loredo M, Bearzi C, Bolli R, Urbanek K, Leri A, Kajstura J, Anversa P: Formation of large coronary arteries by cardiac progenitor cells. Proc Natl Acad Sci U S A 2008;105:1668-1673.

139 Hoffman RM: Recent advances on in vivo imaging with fluorescent proteins. Methods Cell Biol 2008;85:485-495.

140 Hoffman RM: A better fluorescent protein for whole-body imaging. Trends Biotechnol 2008;26:1-4.

141 van Zandvoort M, Engels W, Douma K, Beckers L, Oude Egbrink M, Daemen M, Slaaf DW: Two-photon microscopy for imaging of the (atherosclerotic) vascular wall: A proof of concept study. J Vasc Res 2004;41:54-63.

142 Douma K, Prinzen L, Slaaf DW, Reutelingsperger CP, Biessen EA, Hackeng TM, Post MJ, van Zandvoort MA: Nanoparticles for optical molecular imaging of atherosclerosis. Small 2009;5:544-557. 
143 Kellermayer MS, Karsai A, Kengyel A, Nagy A, Bianco P, Huber T, Kulcsar A, Niedetzky C, Proksch R, Grama L: Spatially and temporally synchronized atomic force and total internal reflection fluorescence microscopy for imaging and manipulating cells and biomolecules. Biophys J 2006;91:2665-2677.

144 Sun Z, Martinez-Lemus LA, Hill MA, Meininger GA: Extracellular matrixspecific focal adhesions in vascular smooth muscle produce mechanically active adhesion sites. Am J Physiol Cell Physiol 2008;295:C268-278.

145 Sun Z, Martinez-Lemus LA, Trache A, Trzeciakowski JP, Davis GE, Pohl U, Meininger GA: Mechanical properties of the interaction between fibronectin and alpha5beta1-integrin on vascular smooth muscle cells studied using atomic force microscopy. Am J Physiol Heart Circ Physiol 2005;289:H2526-2535.

146 Tan Y, Hoffman RM: A highly sensitive single-enzyme homocysteine assay. Nat Protoc 2008;3:1388-1394. 